\title{
Assessing the performance of regional landslide early warning models: the EDuMaP method
}

\author{
M. Calvello and L. Piciullo \\ Department of Civil Engineering, University of Salerno, Fisciano, Italy \\ Correspondence to: L. Piciullo (lucapiciullo@gmail.com)
}

Received: 11 September 2015 - Published in Nat. Hazards Earth Syst. Sci. Discuss.: 8 October 2015

Revised: 14 December 2015 - Accepted: 22 December 2015 - Published: 18 January 2016

\begin{abstract}
A schematic of the components of regional early warning systems for rainfall-induced landslides is herein proposed, based on a clear distinction between warning models and warning systems. According to this framework an early warning system comprises a warning model as well as a monitoring and warning strategy, a communication strategy and an emergency plan. The paper proposes the evaluation of regional landslide warning models by means of an original approach, called the "event, duration matrix, performance" (EDuMaP) method, comprising three successive steps: identification and analysis of the events, i.e., landslide events and warning events derived from available landslides and warnings databases; definition and computation of a duration matrix, whose elements report the time associated with the occurrence of landslide events in relation to the occurrence of warning events, in their respective classes; evaluation of the early warning model performance by means of performance criteria and indicators applied to the duration matrix. During the first step the analyst identifies and classifies the landslide and warning events, according to their spatial and temporal characteristics, by means of a number of model parameters. In the second step, the analyst computes a time-based duration matrix with a number of rows and columns equal to the number of classes defined for the warning and landslide events, respectively. In the third step, the analyst computes a series of model performance indicators derived from a set of performance criteria, which need to be defined by considering, once again, the features of the warning model. The applicability, potentialities and limitations of the EDuMaP method are tested and discussed using real landslides and warning data from the municipal early warning system operating in Rio de Janeiro (Brazil).
\end{abstract}

\section{Introduction}

In generic terms, early warning constitutes a process whereby information generated from tailored observations of natural phenomena is provided to communities at risk, or to institutions which are involved in emergency response operations, so that certain tasks may be executed before a catastrophic event impacts such communities (Villagrán de León et al., 2013). Landslide early warning systems (LEWSs) mitigate the risk to life associated with the occurrence of landslides by temporarily removing people - i.e., the elements at risk - from hazardous areas whenever landslide risk is considered to be unacceptable. According to Glade and Nadim (2014), the installation of an early warning system is often a cost-effective risk mitigation measure and in some instances the only suitable option for sustainable management of disaster risks. Within the landslide risk management framework proposed by Fell et al. (2005), landslide early warning systems may be considered a non-structural passive mitigation option to be employed in areas where risk, occasionally, rises above previously defined acceptability levels.

In the "priority for action 2" established by the Hyogo Framework for Action - i.e., identify, assess and monitor disaster risks and enhance early warning - the following key activity is identified: establish institutional capacities to ensure that early warning systems are subject to regular system testing and performance assessments (Hyogo Framework for Action, 2005). Despite the fact that the scientific literature reports many studies on landslide early warning systems, either addressing a single landslide at slope scale (Lollino et al., 2002; Blikra, 2008; Intrieri et al., 2012; Michoud et al., 2013; Thiebes et al., 2013a; among others) or concurrent phenomena in areas of relevant extension at municipal/regional/national scale (NOAA-USGS (2005), 
Martelloni et al. (2012), Calvello et al. (2015a, b), Stähli et al. (2015), Segoni et al. (2015), among others), no standard requirements exist for assessing their performance. To this aim, many questions need to be addressed, among which are the following: how are data of registered landslides and warnings used to check on the performance of early warning models? How are model errors quantified? How are false alerts (FAs) and missed alerts (MAs) defined when the warning model includes more than two warning levels? What are the most relevant model performance indicators? All the previous questions may be summed up; how should model validation be performed by LEWSs managers? The answer to this question is not trivial, despite what it may seem at first sight.

The performance quantification issue is often overlooked, both by system managers and by researchers dealing with warning models for LEWSs. For instance, the main focus of researchers dealing with warning systems for rainfallinduced landslides at regional scale, which are typically based on empirical rainfall thresholds (Guzzetti et al. (2007) and references therein), is on improving the correlation between rainfall indicators and landslides. However, literature studies rarely back analyze the relationship between warnings, which would have been issued adopting those correlations, and landslides. Especially for LEWSs operating at regional scale (ReLEWSs), empirical evaluations are often carried out by simply analyzing the time frames during which significant high-consequence landslides occurred in the test area (Keefer et al., 1987; Baum and Godt, 2010; Capparelli and Tiranti, 2010; Aleotti, 2004). Alternatively, the performance evaluation is based on 2 by 2 contingency tables computed for the joint frequency distribution of landslides and alerts, both considered as dichotomous variables (Yu et al., 2003; Cheung et al., 2006; Godt et al., 2006; Restrepo et al., 2008; Tiranti and Rabuffetti, 2010; Kirschbaum et al., 2012; Martelloni et al., 2012; Peres and Cancelliere, 2012; Staley et al., 2013; Lagomarsino et al., 2013, 2015; Greco et al., 2013; Segoni et al., 2014; Gariano et al., 2015; Stähli et al., 2015). The four elements of these tables - i.e., correct alerts (CAs) or true positives; missed alerts, false negatives or type II errors; false alerts, false positives or type I errors; true negatives (TNs) - are then used to assess the weight of the correct predictions in relation to the model errors by means of a series of statistical indicators of the model performance. In all these cases, however, model performance is assessed, neglecting some important aspects that are peculiar to ReLEWSs, such as the possible occurrence of multiple landslides in the warning zone, the duration of the warnings in relation to the time of occurrence of the landslides, the level of the issued warning in relation to the landslide spatial density in the warning zone and the relative importance system managers attribute to different types of errors.

This paper proposes a methodology in which the analyst is able to explicitly consider all the above-mentioned aspects for the performance assessment of a landslide regional warning model to be employed within a ReLEWS. The original approach, called the "event, duration matrix, performance (EDuMaP) method, comprises three successive steps: definition and temporal analysis of warning events (WE) and landslide events (LE), computation of a duration matrix and evaluation of the warning model performance. The key element of the EDuMaP method is the definition and computation of a duration matrix, whose elements report the time associated with the occurrence of landslide events in relation to the occurrence of warning events, in their respective classes. The applicability of the EDuMaP method is tested and discussed using both synthetic data and real landslides and warnings data from the municipal early warning system operating in Rio de Janeiro (Brazil).

\section{Landslide early warning systems}

\subsection{Regional systems for rainfall-induced landslides}

Warning systems for landslides can be designed and used at different reference scales. Two categories of LEWSs can be defined on the basis of their scale of analysis and operation: "local" systems and "regional" systems (International Centre of Geohazards, 2012; Thiebes et al., 2012; Calvello et al., 2015b). ReLEWSs are used to assess the probability of occurrence of landslides over appropriately defined homogeneous alert zones of relevant extension, typically through the prediction and monitoring of meteorological variables, in order to give generalized warnings to the population. Differently, the main aim of local landslide warning systems is the temporary evacuation of people from areas where, at specific times, the risk level to which they are exposed is considered to be intolerably high. The scale inevitably also influences the stakeholders involved, the data to be used, the type of forecasting, the emergency phases, the communication strategies and many other activities necessary for designing and operating such systems.

The literature presents many examples of landslide early warning systems operating at local scale (Lollino et al., 2002; Blikra, 2008; Intrieri et al., 2012; Thiebes et al., 2013b; among others), while the scientific references to regional warning systems are much rarer (Wilson (2004), NOAA-USGS (2005), Lagomarsino et al. (2013), Calvello et al. (2015b), Stähli et al. (2015) and references therein). The characteristics of landslide warning systems at local scale are strongly affected by numerous constraints and factors, from time to time different, related to the characteristics of the boundary value problem to address. An interesting contribution aiming at providing guidance for the design of such systems is proposed by the International Centre of Geohazards (2012), wherein the authors deal with the technical and practical issues related to monitoring and early warning for landslides and identify the best technologies available in the context of both hazard assessment and system design. Con- 
cerning regional warning systems, a few examples of systems for rainfall-induced landslides currently operating around the world are presented in the following.

In the USA, the US Geological Survey has long been working on ReLEWSs in a number of states: California, Colorado, Oregon and Washington (Chleborad, 2000; Chleborad et al., 2008; Baum and Godt, 2010; NOAA-USGS, 2005; Cannon et al., 2011). The state of knowledge and resources available to issue alerts of precipitation-induced shallow, rapidly moving landslides and debris flows vary across the USA; for instance, in the city of Seattle, WA, the alert system includes four levels - Null, Outlook, Watch and Alarm - and warnings are based on the measured or expected exceedance of cumulated rainfall and intensity-duration thresholds combined with criteria using monitored soil moisture (Godt et al., 2006). In Hong Kong (Chan and Pun, 2004; Cheung et al., 2006; http://www.weather.gov.hk/wservice/ warning/landslip.htm), the correlation model between rainfall events and landslides is based on an increasing probability of landslide occurrence depending on the measured rolling $24 \mathrm{~h}$ rainfall for four different types of man-made slopes: soil cuts, rock cuts, fills and retaining structures. In Japan, a nationwide early warning system for landslide disasters was created by the government in 2005 (Osanai et al., 2010); the occurrences of debris flows and slope failures are related to several rainfall indices (e.g., 60' cumulative rainfall, soil-water index), whose thresholds have been mainly computed considering rainfall data recorded as not triggering disasters. In Brazil, the municipal system operating in Rio de Janeiro (d'Orsi et al., 1997; d'Orsi, 2012; Calvello et al., 2015a, b) issues two different co-existing alert sets, rainfall warnings and landslide warnings; the landslide warnings are based on the comparison between rainfall measured by the monitoring stations and rainfall thresholds and they are related to an expected spatial density of landslides. In Europe, two national systems for rainfall-induced landslides have been recently implemented: one in Norway, managed by the Norwegian Water Resources and Energy Directorate (Devoli et al., 2015), and the other in Italy, designed and operated by the research center CNR-IRPI on behalf of the national civil protection (Rossi et al., 2012). The Norwegian system is a national early warning system for landslides and floods, with the aim of assisting road and railway authorities, as well as local authorities and policy makers, in taking preventive measures before the occurrence of potentially dangerous events. The Italian system, which is called SANF, is based on sub-hourly rainfall measurements obtained by a national network of 1950 rain gauges, quantitative rainfall forecasts and cumulated rainfall-duration rainfall thresholds. Besides the national system, following a recent national law written on this subject (DPCM, 2004), other relevant experiences are also present in many Italian regions, such as in Emilia Romagna (Berti et al., 2012; Lagomarsino et al., 2013), Piemonte (Tiranti and Rabuffetti, 2010), Campania (DGR n. 299/2005), Toscana (DGR n. 895/2013, DGR

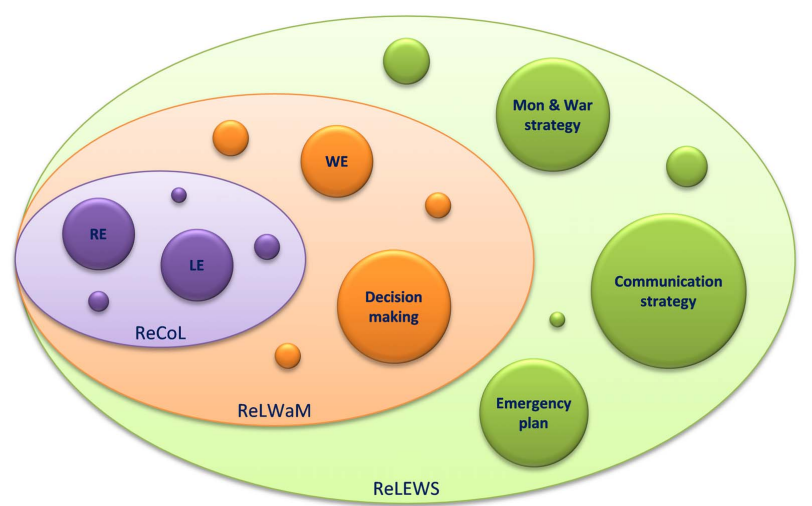

Figure 1. Scheme of the components of regional early warning systems for rainfall-induced landslides. Legend: RE is rainfall events; $\mathrm{LE}$ is landslide events; WE is warning events; ReCoL is regional correlation law; ReLWaM is regional landslide warning model; ReLEWS is regional landslide early warning system.

\section{n. 395/2015), Umbria (DGR n. 2312/2007) and Sicily (DPRS n. 626/2014).}

\subsection{Early warning systems, warning models and correlation laws}

Di Biagio and Kjekstad (2007) use a block diagram to propose a schematic of the structure of landslide early warning systems in four main steps: monitoring, data analysis and forecasting, warning and response. Bell et al. (2008) propose a scheme of integrated LEWSs combining both the natural scientific components (e.g., geotechnics, engineering, data measurement, transmission and storage, analysis) and the social system (e.g., legal framework, demands from different stakeholders). Intrieri et al. (2013) describe LEWSs as the balanced combination of four main activities: design, monitoring, forecasting and education. Calvello et al. (2015b) state that the objectives of LEWSs should be defined by considering the scale of analysis and the type of landslides; they also represent the process of designing and managing landslide early warning systems by a "wheel" with four concentric rings identifying: the necessary skills, the activities to be performed, the means to be used and the basic elements of the system.

Figure 1 and Table 1 show an original schematic of the components of regional early warning systems for rainfallinduced landslides. The proposed scheme is based on a clear distinction among correlation laws, warning models and warning systems. Within this framework, a regional correlation law for rainfall-induced landslides, is defined as a functional relationship between RE and LE (see Sect. 3.1 for details on the definition, classification, identification and analysis of landslide events), eventually including other relevant monitored variables. A regional landslide warning model includes the regional correlation law as well as warning events 
Table 1. Components of regional landslide early warning systems (ReLEWS) for rainfall-induced landslides, relevance for system parts - i.e., regional correlation law (ReCoL), regional landslide warning model (ReLWaM) - and system actors - i.e., citizens, managers and scientists.

\begin{tabular}{|c|c|c|c|c|c|c|}
\hline \multirow[t]{2}{*}{ Components } & \multicolumn{3}{|c|}{ Relevance for system parts } & \multicolumn{3}{|c|}{ Relevance for system actors } \\
\hline & $\mathrm{ReCoL}$ & ReLWaM & ReLEWS & Citizens & Managers & Scientists \\
\hline Warning events & yes & yes & yes & & yes & yes \\
\hline Landslide events & yes & yes & yes & & yes & yes \\
\hline Other variables & yes & yes & yes & & yes & yes \\
\hline Warning events & & yes & yes & yes & yes & partly \\
\hline Decision-making & & yes & yes & yes & yes & partly \\
\hline Monitoring and warning strategy & & & yes & & yes & yes \\
\hline Communication strategy & & & yes & yes & yes & yes \\
\hline Emergency plan & & & yes & yes & yes & partly \\
\hline
\end{tabular}

(see Sect. 3.1 for details on the definition, classification, identification and analysis of warning events) and decisionmaking procedures to issue the warnings. ReLEWS includes the regional warning model and the following components: monitoring and warning strategy, communication strategy and emergency plan. Each component of ReLEWs may also be related to a number of actors involved with their deployment, operational activities and management. As reported in Table 1, three classes of such actors are herein identified: citizens, managers and scientists. All the system components are relevant for more than one class of actor. For instance, it is important to highlight that both the decision-making and emergency plan components, within which the evacuation procedures and the procedures used to issue and withdraw the warnings are defined, are significantly influenced by people's risk perception as well as by operational aspects the managers need to address in cooperation with the scientists.

\section{Framework for the performance analysis of regional landslide warning models}

Maskrey (1997) states that the effectiveness of an early warning system should be judged less on whether warnings are issued per se but rather on the basis of whether the warnings facilitate appropriate and timely decision-making by those most at risk. Calvello et al. (2015b) state that the design of landslide warning systems require synergy between technical and social skills. According to them, the main objective of the designers of the technical subsystem is the definition of efficient processes, while the procedures defined within the social subsystem are important in making landslide early warning systems an effective tool to reduce risk to life.

Following the previous statements and the scheme proposed in Fig. 1, the technical performance of a regional landslide early warning system is herein evaluated by means of the EDuMaP method (Fig. 2), which assesses the performance of the warning model, employed by that system. The

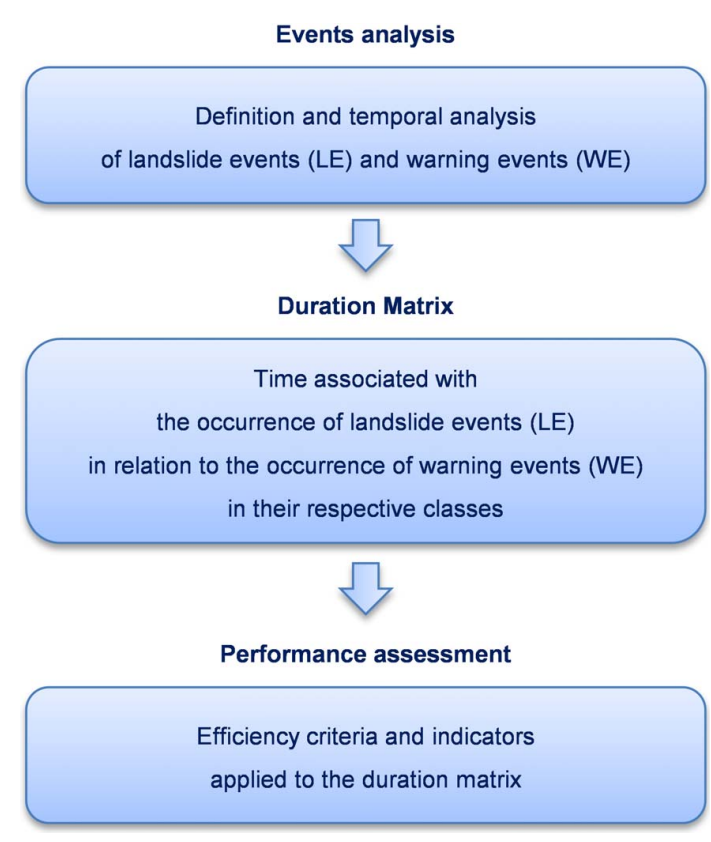

Figure 2. Scheme of the "events, duration matrix, performance" (EDuMaP) method.

EDuMaP method comprises the following three successive steps:

- events analysis, i.e., LE and WE derived from available landslides and warnings databases;

- definition and computation of a duration matrix, whose elements report the time associated with the occurrence of landslide events in relation to the occurrence of warning events, in their respective classes;

- evaluation of the early warning model performance by means of performance criteria and indicators applied to the duration matrix computed in the previous step. 
Table 2. Input parameters for the classification, identification and temporal analysis of landslide events (LE) and warning events (WE).

\begin{tabular}{lll}
\hline Parameters of the events analysis & Symbol & Relevant for \\
\hline 1. Warning levels & $W_{\text {lev }}$ & Classification of WE \\
2. Landslide density criterion & $L_{\mathrm{den}(k)}$ & Classification of LE \\
3. Lead time & $t_{\mathrm{LEAD}}$ & Identification of WE \\
4. Landslide typology & $L_{\mathrm{typ}}$ & Identification of LE \\
5. Minimum interval between landslide events & $\Delta t_{\mathrm{LE}}$ & Identification of LE \\
6. Over time & $t_{\mathrm{OVER}}$ & Identification of LE \\
7. Area of analysis & $A$ & Temporal analyses of LE and WE \\
8. Spatial discretization adopted for warnings & $\Delta A_{(k)}$ & Temporal analyses of LE and WE \\
9. Time frame of analysis & $\Delta T$ & Temporal analyses of LE and WE \\
10. Temporal discretization of analysis & $\Delta t$ & Temporal analyses of LE and WE \\
\hline
\end{tabular}

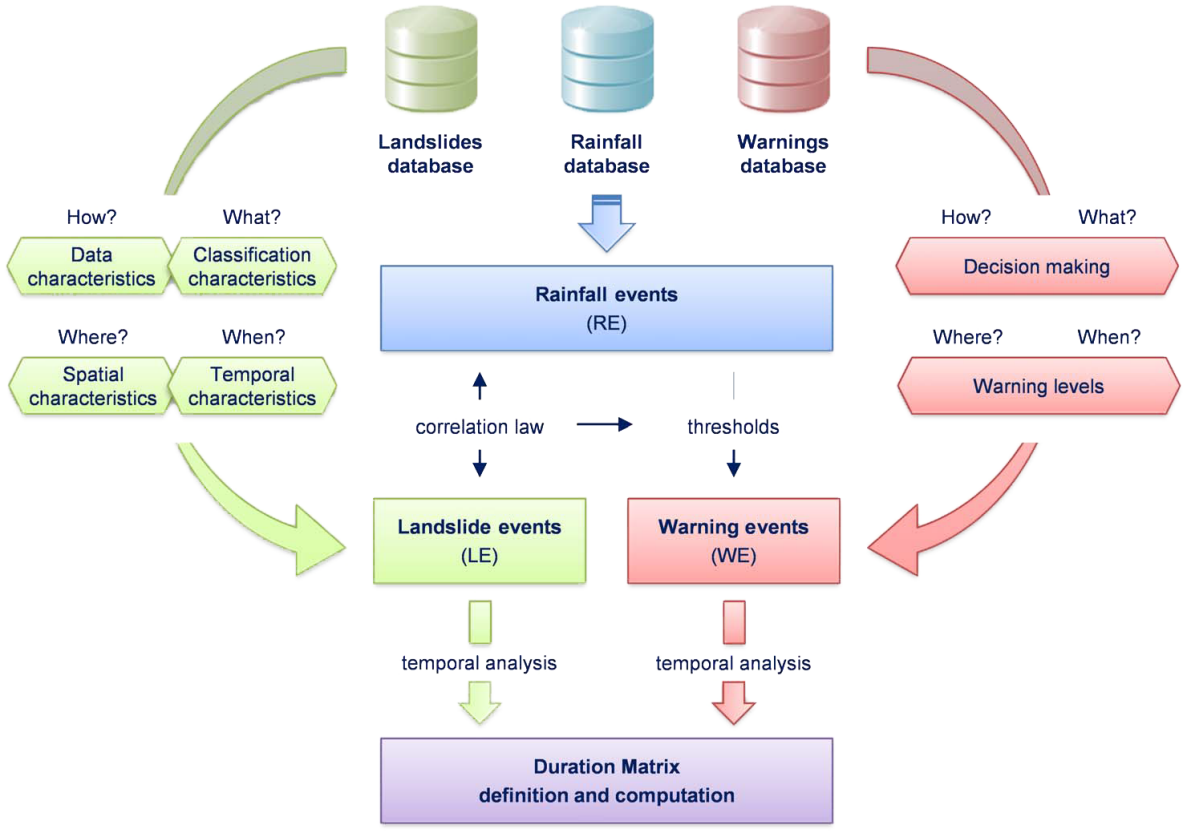

Figure 3. Scheme of the relationships among rainfall events, landslide events and warning events for the definition and computation of the duration matrix.

\subsection{Events analysis: landslide and warning events}

Despite the fact that regional warning models typically associate descriptors with their warning levels which consider the potential number of landslides affecting the warning zone, only few examples exist, in the literature, that evaluate the system performance differentiating among warning levels and among the number of concurrent landslides registered during the warning phases (Yu et al., 2003; Calvello et al., 2015b). The "events analysis" step of the EDuMaP method aims at defining the most appropriate LE and WE to be used to assess the model performance. To this aim, databases of recorded landslides and warnings must be available (Fig. 3). The results of the analysis depend on the values assumed by a series of well-identified parameters (Table 2), which are de- fined to allow the analyst to make choices on how to select and group landslides and warnings.

Figure 3 exemplifies the relationships among rainfall, landslide and warning data for the performance analysis of a warning model employed for rainfall-induced landslides within regional systems. The assessment of the model performance requires the preliminary identification of LE and WE from analyses carried out, respectively, on landslide and warning databases. Landslide events are herein defined as a series of landslides grouped on the basis of their characteristics, so as to implicitly evaluate and classify the magnitude of a set of multiple phenomena occurring in a given area within a given time period. Landslide events are retrieved from the landslides database according to data, classification, spatial and temporal characteristics of the landslide records. As reported in the figure, the previous four characteristics 
Table 3. Examples of landslide density criteria which can be used to classify the landslide events.

\begin{tabular}{|c|c|c|c|}
\hline $\begin{array}{l}\text { LE } \\
\text { class }\end{array}$ & $\begin{array}{l}\text { Absolute } \\
\text { criterion } \\
\text { (no. of } \\
\text { landslides) }\end{array}$ & $\begin{array}{l}\text { Relative criterion } \\
\text { (no. of landslides/area) }\end{array}$ & Mixed criterion \\
\hline 1 & 0 & 0 & 0 \\
\hline 2 & 1 & from 0.001 to $0.02 \mathrm{~km}^{2}$ & 1 \\
\hline 3 & 2 to 10 & from 0.021 to $0.1 \mathrm{~km}^{2}$ & from 2 to $\operatorname{MIN}\left(10 ; 0.1 \mathrm{~km}^{2}\right)$ \\
\hline 4 & $>10$ & $>0.1 \mathrm{~km}^{2}$ & $>\operatorname{MIN}\left(10 ; 0.1 \mathrm{~km}^{2}\right)$ \\
\hline
\end{tabular}

may be associated with the following four questions words: how (e.g., how does the database report landslide data?), what (e.g., what types of landslides are relevant for the warning model?), where (e.g., where did landslides occur in relation to the alert zones of the warning system?) and when (e.g., when did landslides occur?). Warning events are herein defined a set of warning levels issued within a given warning zone, grouped considering their temporal characteristics. Warning events are retrieved from the warnings database according to decision-making and warning levels criteria, respectively, addressing the procedures employed to activate the warnings and the meaning of the warning levels in relation to the warnings issued in the alert zones. Looking at the proposed scheme, it is evident that the identification and computation of the duration matrix (see following section for a detailed explanation of the second step of the EDuMaP method) does not require rainfall data, as it only depends on temporal analyses carried out on the landslide and warning events. For completeness, however, the figure also reports the typical relationships employed among rainfall, landslide and warning events. Warning events (i.e., the warning model output) are indeed typically generated by evaluating the characteristics of the monitored rainfall in relation to appropriately defined rainfall thresholds, which are in turn based on a correlation law between rainfall events (i.e., the triggering factor) and landslide events (i.e., the hazard for which warnings are issued).

The identification of landslide events and warning events from the respective databases is influenced by a series of choices the analyst needs to make in selecting and grouping, respectively, landslides and warnings. These choices must be carried out considering the characteristics of the warning model whose performance the analyst wants to assess. Table 2 reports the 10 parameters which need to be defined to carry on the events analysis:

1. warning levels, $W_{\text {lev }}$, i.e., number of warning classes used by the model;

2. landslide density criterion, $L_{\operatorname{den}(k)}$, i.e., thresholds used to differentiate among $k$ classes of landslide events on the basis of their spatial characteristics;
3. lead time, $t_{\text {LEAD }}$, i.e., value of the time interval between the sending out of the first warning level identified within a warning event and the assumed beginning of the warning event;

4. landslide typology, $L_{\mathrm{typ}}$, i.e., landslides addressed by the warning model;

5. minimum interval between landslide events, $\Delta t_{\mathrm{LE}}$, i.e., time quantifying the maximum temporal gap among landslides included within a single landslide event;

6. over time, $t_{\mathrm{OVER}}$, i.e., time interval between the last landslide identified within a landslide event and the assumed ending of the landslide event;

7. area of analysis, $A$, i.e., area for which both landslides and warnings data are available;

8. spatial discretization adopted for warnings, $\Delta A_{(k)}$, i.e., subdivision of the area of analysis in $k$ classes on the basis of the spatial criteria adopted to issue the warnings;

9. time frame of analysis, $\Delta T$, i.e., temporal length of databases for which both landslides and warnings data are available;

10. temporal discretization of analysis, $\Delta t$, i.e., minimum unit of time used to identify landslide and warning events.

The first two parameters, $W_{\text {lev }}$ and $L_{\operatorname{den}(k)}$, are relevant for the classification of the warning and landslide events, respectively. Concerning the second parameter, Table 3 reports three examples of landslide density criteria which could be used to classify landslide events in four classes: the first criterion is based on the number of landslides, the second one on the number of landslides per unit area and the third one is a combination of the previous two. The following four parameters are relevant for the identification of the warning and landslide events. In particular, $L_{\text {typ }}$ is used to select, from the landslides database, only the landslides which are considered relevant for the early warnings. The meaning of $t_{\mathrm{LEAD}}, \Delta t_{\mathrm{LE}}$ and $t_{\text {OVER }}$ is schematized in Fig. 4. Figure 4a reports one 


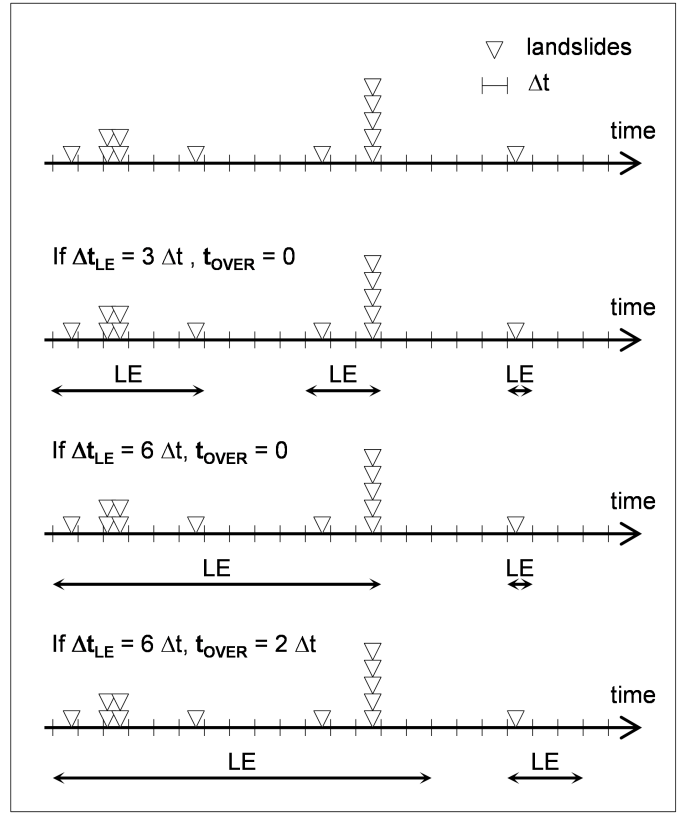

(a)

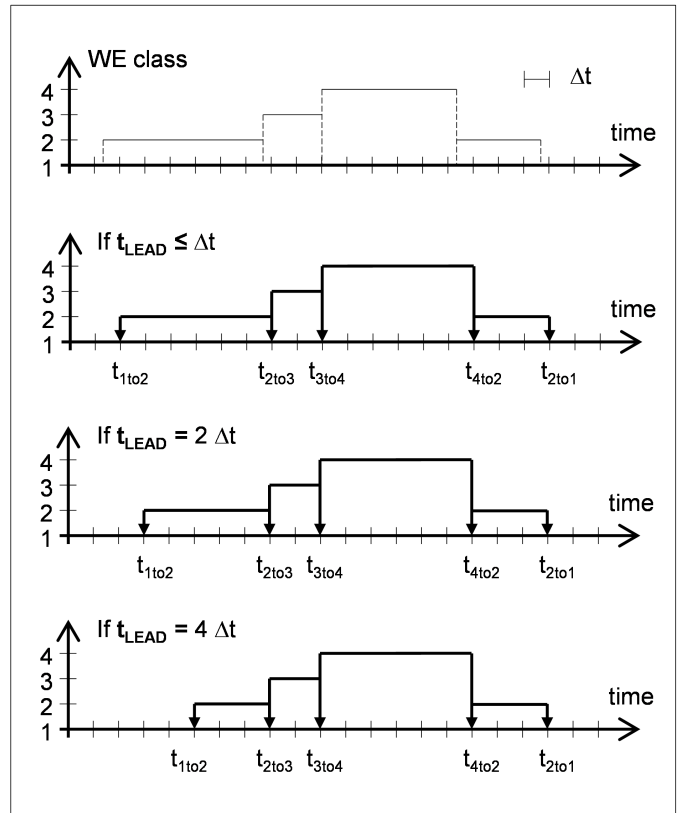

(b)

Figure 4. Exemplification of the meaning of parameters: minimum interval between landslide events, $\Delta t_{\mathrm{LE}}$, and over time, $t_{\mathrm{OVER}}(\mathbf{a})$; lead time, $t_{\text {LEAD }}(\mathbf{b})$.

set of landslides and three series of landslide events identified considering three different combination of values for $\Delta t_{\mathrm{LE}}$ and $t_{\mathrm{OVER}}$. Figure $4 \mathrm{~b}$ reports one set of warning levels (in four classes) and three series of warning events identified considering three different values of $t_{\mathrm{LEAD}}$. It is important to highlight that the latter two variables should be seen as time variables which are relevant for decision-making purposes. The lead time is related, for instance, to how evacuation procedures are defined within the warning system; the over time may be related to the procedures issued to withdraw the warnings. The last four parameters, whose meaning is straightforward, are relevant for the temporal analyses of both landslide events and warning events.

\subsection{Duration matrix}

The key element of the numerical evaluation of the performance of a warning model is the definition and computation of a matrix, herein called "duration matrix" (Fig. 5), whose elements report the time associated with the occurrence of landslide events in relation to the occurrence of warning events, in their respective classes. The classification of landslide events and warning events (see parameters $L_{\mathrm{den}}$ and $W_{\text {lev }}$ in Table 2) establishes the structure of the duration matrix. Indeed, the number of rows and columns of the matrix is equal to the number of classes defined for the warning and landslide events, respectively. The matrix reported in Fig. 5a is drawn as a 4 by 4 matrix, under the hypothesis of four classes of warning events, indicated with num- bers from 1 to 4 and letters representing the descriptors no, medium, high and very high, and four classes of landslide events, indicated with numbers from 1 to 4 and letters representing the descriptors no, small, intermediate and large. Each element of the duration matrix, $d_{i j}$, is computed, within the time frame of the analysis, $\Delta T$, as follows:

$d_{i j}=\sum_{\Delta T}$ time $_{i j}$

where $i$ is the number of classes of the warning events, $j$ is the number of classes of the landslide events and time $i j$ is amount of time for which a class $i$ th warning events is concomitant with a class $j$ th landslide event.

Figure $5 \mathrm{~b}$ shows a graphical example of temporal analysis needed for the computation, following Eq. (1), of the elements of the duration matrix. It is important to highlight that the dimension of the elements of the duration matrix, $d_{i j}$, is time and that the sum of all elements, $\sum_{i j} d_{i j}$, is always equal to the time frame of the analysis, $\Delta T$.

To further clarify how the duration matrix is computed, Tables 4 and 5 report a set of synthetic data exemplifying the performance of a fictitious regional landslide warning model, herein created considering a time frame of 1 year (the year 2000). Table 4 shows the set of warnings issued by the model - together with the information which are supposedly retrieved from the warnings database - and the corresponding warning events. Table 5 shows the set of landslides recorded during the same time frame - together with the information retrieved from the landslides database - and 
Table 4. Synthetic data exemplifying the performance of a regional landslide warning model: warnings issued and corresponding warning events.

\begin{tabular}{llllll}
\hline & \multicolumn{2}{c}{ Warnings issued } & \multicolumn{2}{c}{ Warning event } \\
\cline { 3 - 6 } Level & From (date and hour) & To (date and hour) & $\begin{array}{l}\text { Duration } \\
\text { (h:mm) }\end{array}$ & ID & Class \\
\hline Medium & 13 Jan 2000 13:00 & 13 Jan 2000 16:00 & 3:00 & WE_2000_01 & 2 (M) \\
High & 13 Jan 2000 16:00 & 13 Jan 2000 17:30 & $1: 30$ & WE_2000_01 & 3 (H) \\
Very high & 13 Jan 2000 17:30 & 14 Jan 2000 06:00 & 12:30 & WE_2000_01 & 4 (VH) \\
Medium & 14 Jan 2000 06:00 & 14 Jan 2000 18:00 & 12:00 & WE_2000_01 & 2 (M) \\
High & 18 Mar 2000 07:30 & 18 Mar 2000 18:00 & 10:30 & WE_2000_02 & 3 (H) \\
Medium & 22 Nov 2000 10:00 & 22 Nov 2000 12:00 & 2:00 & WE_2000_03 & 2 (M) \\
Very high & 22 Nov 2000 12:00 & 23 Nov 2000 07:30 & 19:30 & WE_2000_03 & 3 (H) \\
\hline
\end{tabular}

\begin{tabular}{|c|c|c|c|c|c|}
\hline & \multicolumn{4}{|c|}{ Landslide Events duration } \\
\hline & & $1(\mathrm{no})$ & 2 (S) & $3(1)$ & $4(\mathrm{~L})$ \\
\hline \multirow{4}{*}{ 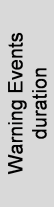 } & 1 (no) & $d_{11}$ & $d_{12}$ & $d_{13}$ & $\mathrm{~d}_{14}$ \\
\hline & 2 (M) & $d_{21}$ & $d_{22}$ & $d_{23}$ & $d_{24}$ \\
\hline & $3(\mathrm{H})$ & $d_{31}$ & $d_{32}$ & $d_{33}$ & $d_{34}$ \\
\hline & $4(\mathrm{VH})$ & $d_{41}$ & $d_{42}$ & $d_{43}$ & $d_{44}$ \\
\hline
\end{tabular}

(a)

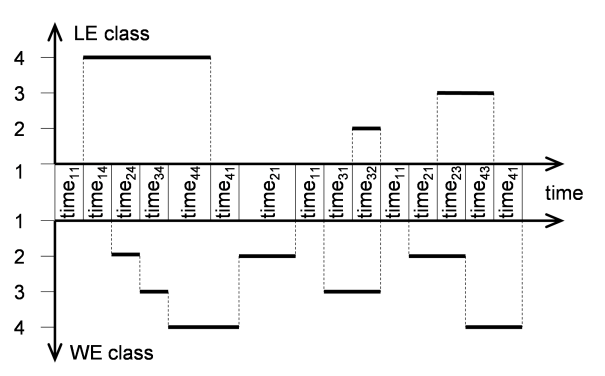

(b)

Figure 5. Structure of the duration matrix (a) and graphical exemplification of the temporal analysis needed for its computation (b).

the corresponding landslide events. Both the warning and the landslide events have been derived following the procedure described in the previous section, assuming the following parameters' values: four warning levels, $W_{\text {lev }}$; landslide density thresholds, $L_{\mathrm{den}}$, equal to 0 (class 1 ), 1 (class 2), 2 to 10 (class 3 ), $>10$ (class 4 ); lead time, $t_{\mathrm{LEAD}}$, equal to $0 ; L_{\mathrm{typ}}$ equal to all the landslides recorded in the database, independently of the values assumed by typology and accuracy of time record; minimum interval between landslide events, $\Delta t_{\mathrm{LE}}$, equal to $12 \mathrm{~h}$; over time, $t_{\mathrm{OVER}}$, equal to 0 ; constant area of analysis, $A$; spatial discretization adopted for warnings, $\Delta A_{(k)}$, equal to the area of analysis; time frame of the analysis, $\Delta T$, equal to 1 year; temporal discretization of the analysis, $\Delta t$, equal to $1 \mathrm{~h}$.

Three landslide events occurred in the year 2000, herein identified as LE_2000_01 (from 13 to 14 January), LE_2000_02 (18 March) and LE_2000_03 (22 November), and classified in the following classes: 4 (L), 2 (S), 3 (I). On the same dates of the landslide events, the following three warning events are recorded: WE_2000_01 (from 13:00 LT on 13 January to 18:00 LT on 14 January), with warning levels varying from 2 (M) to 4 (VH); WE_2000_02 (from 07:30 to 18:00 LT on 18 March), with warning level equal to 3 (M); WE_2000_03, (from 10:00 LT on 22 November to 19:30 LT on 23 November) with warning levels varying from $2(\mathrm{M})$ to $3(\mathrm{H})$. The total number of distinct warning lev- els issued is, in this case, equal to seven. Table 6 and Fig. 6 report the result of the temporal analysis conducted, for the year-long time frame, on these events. The resulting duration matrix is shown in Fig. 6.

\subsection{Performance assessment: criteria and indicators}

Typically, the evaluation of system performance and accuracy uses statistical indicators derived from 2 by 2 contingency tables. It is straightforward to understand that a good performance of a regional landslide warning model must be associated to few missed and false alerts. However, when landslide events and warning events are not expressed as dichotomous variables, the identification of missed or false alerts is not unambiguous. To properly evaluate performance, another key issue to consider is the relative importance assigned by the system managers to the different types of errors. The latter is, in turn, related to the meaning assigned to the warnings issued in the alert zones in terms of expected number of landslides. To address these issues, the "performance assessment" step of the EDuMaP method is based on the definition of a series of performance criteria and indicators applied to the duration matrix.

A first judgment on the results from the duration matrix may be based on the computation of the distribution of landslide events and warning events in relation to each other, in 
Table 5. Synthetic data exemplifying the performance of a regional landslide warning model: landslide database and corresponding landslide events.

\begin{tabular}{|c|c|c|c|c|c|}
\hline \multicolumn{4}{|c|}{ Landslide database } & \multicolumn{2}{|c|}{ Landslide event } \\
\hline Number & Typology & Date and hour & Accuracy of time record & ID & class \\
\hline 1 & A & 13 Jan 2000 10:20 & exact time & LE_2000_01 & $4(\mathrm{~L})$ \\
\hline 15 & A & 13 Jan $200010: 00$ to $11: 00$ & time interval & LE_2000_01 & $4(\mathrm{~L})$ \\
\hline 3 & $\mathrm{~B}$ & 13 Jan $200010: 00$ to $11: 00$ & interval estimated & LE_2000_01 & $4(\mathrm{~L})$ \\
\hline 2 & A & 13 Jan 2000 12:35 & exact time & LE_2000_01 & $4(\mathrm{~L})$ \\
\hline 1 & $\mathrm{~B}$ & 13 Jan 2000 12:40 & exact time & LE_2000_01 & $4(\mathrm{~L})$ \\
\hline 4 & A & 13 Jan $200012: 00$ to $13: 00$ & time interval & LE_2000_01 & $4(\mathrm{~L})$ \\
\hline 2 & $\mathrm{C}$ & 13 Jan $200012: 00$ to $13: 00$ & time interval & LE_2000_01 & $4(\mathrm{~L})$ \\
\hline 3 & A & 13 Jan $200013: 00$ to $14: 00$ & interval estimated & LE_2000_01 & $4(\mathrm{~L})$ \\
\hline 1 & A & 13 Jan 2000 19:15 & exact time & LE_2000_01 & $4(\mathrm{~L})$ \\
\hline 1 & $\mathrm{~B}$ & 13 Jan 2000 19:20 & exact time & LE_2000_01 & $4(\mathrm{~L})$ \\
\hline 2 & A & 13 Jan $200020: 00$ to $21: 00$ & time interval & LE_2000_01 & $4(\mathrm{~L})$ \\
\hline 7 & A & 13 Jan $200021: 00$ to $22: 00$ & time interval & LE_2000_01 & $4(\mathrm{~L})$ \\
\hline 2 & $\mathrm{~B}$ & 13 Jan $200021: 00$ to $22: 00$ & time interval & LE_2000_01 & $4(\mathrm{~L})$ \\
\hline 1 & A & 14 Jan 2000 01:45 & exact time & LE_2000_01 & $4(\mathrm{~L})$ \\
\hline 1 & A & 18 Mar 2000 12:30 & exact time & LE_2000_02 & $2(\mathrm{~S})$ \\
\hline 1 & A & 18 mar $200017: 00$ to $18: 00$ & time interval & LE_2000_02 & $2(\mathrm{~S})$ \\
\hline 2 & A & 22 Nov $200011: 00$ to $12: 00$ & time interval & LE_2000_03 & $3(\mathrm{I})$ \\
\hline 1 & $\mathrm{~B}$ & 22 Nov 2000 13:20 & exact time & LE_2000_03 & $3(\mathrm{I})$ \\
\hline 2 & A & 22 Nov $200016: 00$ to $17: 00$ & time interval & LE_2000_03 & $3(\mathrm{I})$ \\
\hline 1 & $\mathrm{C}$ & 22 Nov $200016: 00$ to $17: 00$ & interval estimated & LE_2000_03 & $3(\mathrm{I})$ \\
\hline
\end{tabular}
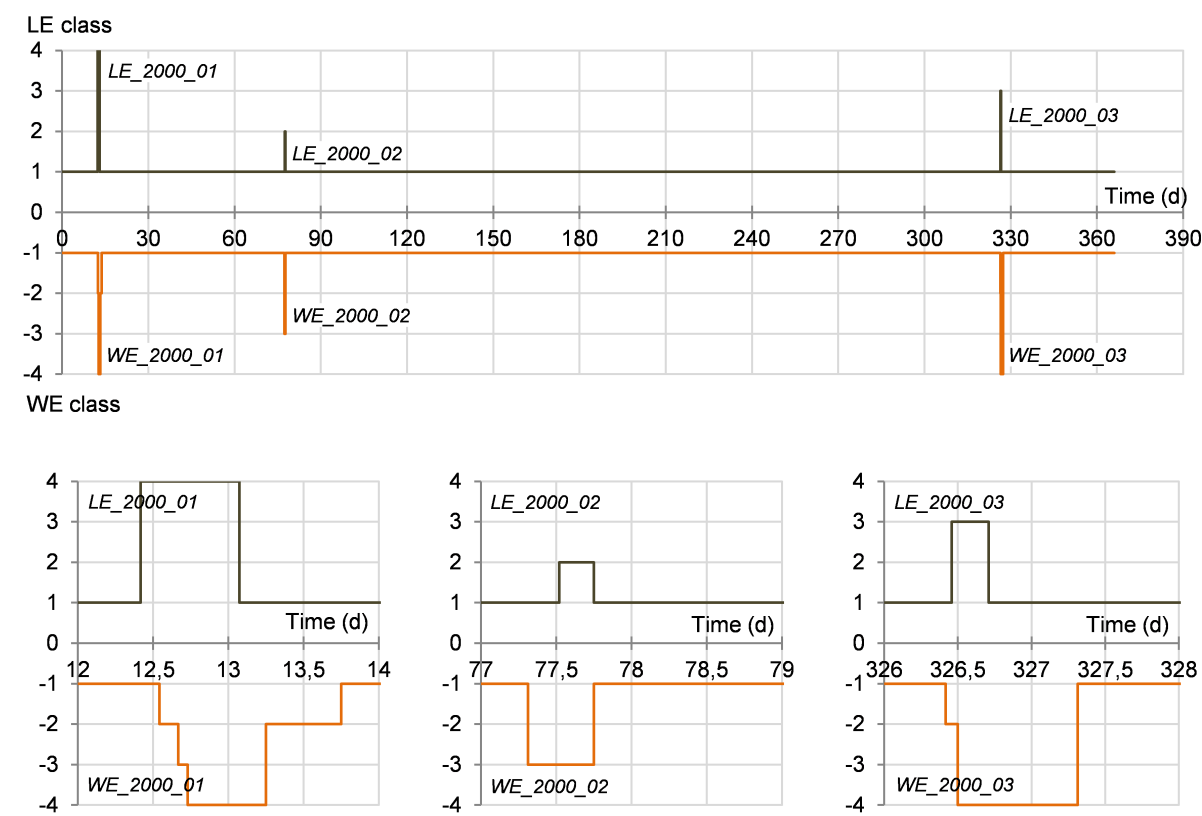

Figure 6. Graphical representation of temporal analysis reported in Table 6.

their respective classes. To this purpose, the following matrix normalizations may be employed:

$$
\begin{aligned}
& \text { d_LE } i j=\frac{d_{i j}}{\sum_{k=1}^{4} d_{k j}} \mathrm{~N}_{-} L E_{j}(\text { for } j=2-4), \\
& {\mathrm{d} \_W E_{i j}}^{=}=\frac{d_{i j}}{\sum_{k=1}^{4} d_{i k}} \mathrm{~N}_{-} \mathrm{WL}_{i}(\text { for } i=2-4),
\end{aligned}
$$


where $d_{i j}$ is the element of the original duration matrix, $\mathrm{d}_{-} \mathrm{LE}_{i j}$ is the element of the duration matrix normalized in relation to the landslide events, $\mathrm{N}_{-} \mathrm{LE}_{j}$ is the number of landslide events classified as class $j$ within the time frame of the analysis, $\mathrm{d}_{-} \mathrm{WE}_{i j}$ is the element of the duration matrix normalized in relation to the warning events and $\mathrm{N}_{-} \mathrm{WL}_{i}$ is the number of warning levels of class $i$ within in the time frame of the analysis.

Figure 7 reports a graphical representation of a more comprehensive analysis of the duration matrix based on a set of two performance criteria, both of them assigning a performance meaning to all but one element of the matrix, $d_{11}$, which expresses the number of hours when no warnings are issued and no landslides occur. Both criteria purposefully neglect element $d_{11}$, whose value is typically orders of magnitude higher than the values of the other elements, in order to allow a more useful relative assessment of the information located in the remaining part of the duration matrix. The first criterion (A) fulfills the task of employing an alert classification scheme derived from a 2 by 2 contingency table, thus identifying CAs, FAs, MAs and TNs. The second criterion (B) assigns a color code to the elements of the matrix in relation to their grade of correctness, herein classified in four classes as follows: green (Gre) for the elements which are assumed to be representative of the best model response, yellow (Yel) for elements representative of minor model errors, red (Red) for elements representative of a significant model errors and purple (Pur) for elements representative of the worst model errors.

A number of performance indicators may be derived from the two performance criteria previously described. Table 8 reports their names, symbols, formulas and values (computed using the duration matrix data from Table 7). The performance indicators related to the alert classification criterion (A) are a series of statistical indicators which are commonly derived from contingency tables: efficiency index, also called efficiency (Martelloni et al., 2012; Lagomarsino et al., 2013) or accuracy (Kirschbaum et al., 2012); hit rate (Tiranti and Rabuffetti, 2010; Cheung et al., 2006), also called sensitivity (Martelloni et al., 2012; Lagomarsino et al., 2013), probability of detection (Kirschbaum et al., 2012; Restrepo et al., 2008; Gariano et al., 2015) or true positive rate (Staley et al., 2013); predictive power, also called positive predictive power (Martelloni et al., 2012); threat score (Staley et al., 2013; Tiranti and Rabuffetti, 2010), also called critical success index (Cheung et al., 2006); odds ratio (Martelloni et al., 2012); misclassification rate (Martelloni et al., 2012); missed alert rate, also called false negative rate (Martelloni et al., 2012; Lagomarsino et al., 2013); and false alert rate, also called probability of false alarms (Gariano et al., 2015). The other performance indicators, either related to the grade of correctness criterion (B) or to both criteria at once, have been named and defined following a similar reasoning.

\section{Application of proposed method to a case study}

\subsection{The Alerta Rio early warning system}

The territory of the city of Rio de Janeiro (Brazil) has long been affected by landslides which often caused, in the last decades, widespread destruction and a significant number of casualties in different areas of the city. The high frequency of these phenomena is to be ascribed both to the geologic, geomorphologic and climatic characteristics of the city (i.e., weathered soils, extensive mountainous areas and a tropical climate) and to the presence of areas characterized by high density of population and by unplanned and spontaneous land occupation (e.g., Coelho Netto et al., 2007). The "Alerta Rio" system (d'Orsi et al., 2004; Calvello et al., 2015b) is a ReLEWS operated by the GEO-Rio Foundation in the municipality of Rio de Janeiro, Brazil, designed to inform stakeholders of the possible occurrence of rainfall induced landslides. The municipality of Rio de Janeiro covers around $1200 \mathrm{~km}^{2}$ and is divided, for warning purposes, into four alert zones (Fig. 8): Baia de Guanabara $\left(390 \mathrm{~km}^{2}\right)$, Zona Sul $\left(40 \mathrm{~km}^{2}\right)$, Baia de Sepetiba $\left(492 \mathrm{~km}^{2}\right)$ and Jacarepaguà $\left(302 \mathrm{~km}^{2}\right)$. Landslide warnings are currently based on the comparison between rainfall measured by a network of 33 rain gauges and rainfall thresholds defined considering the antecedent cumulated rainfall for the following three durations: 1,24 and $96 \mathrm{~h}$. The three cumulated rainfall measures are treated independently by means of a series of either/or rules which define warning levels associated to four landslide probabilities of occurrence: (1) low, if mass movements triggered by rainfall are not expected; (2) medium, if only occasional occurrences of landslides triggered by rainfall are expected, predominantly in artificial slopes; (3) high, for an expected diffuse occurrence of landslides in both natural and artificial slopes; (4) very high, if the expected areal distribution of landslides is significant and the phenomena are expected to be widespread in slopes and roads cuts. Landslide warnings are issued, at any given time, over the whole affected alert zone without explicitly differentiating among areas characterized by different levels of landslide susceptibility, as defined by a municipal susceptibility map available at $1: 10000$ (D'Orsi, 2012). This landslide susceptibility map is also reported in Fig. 8 because the parametric analysis presented in the following sections to evaluate the performance of the Alerta Rio warning model according to the EDuMaP method allows us to explicitly consider the extent of the area most susceptible to landslides for the classification of the landslide events (i.e., definition of the input parameter $\left.L_{\operatorname{den}(k)}\right)$.

\subsection{Setup of parametric analysis}

The analysis presented herein uses data on recorded landslides and issued warnings of the Alerta Rio system for the 3-year period 2010-2012 in two alert zones: Baia de Gua- 
Table 6. Temporal analysis of warning events (WE) and landslide events (LE) using data from Tables 4 and 5.

\begin{tabular}{|c|c|c|c|c|c|c|}
\hline \multicolumn{3}{|c|}{ Time } & \multicolumn{2}{|c|}{ Warning event } & \multicolumn{2}{|c|}{ Landslide event } \\
\hline From (date and hour) & To (date and hour) & Duration (h) & ID & Class & ID & Class \\
\hline 1 Jan 2000 00:00 & 13 Jan 2000 10:00 & 298 & & 1 & & 1 \\
\hline 13 Jan 2000 10:00 & 13 Jan 2000 13:00 & 3 & & 1 & LE_2000_01 & 4 \\
\hline 13 Jan 2000 13:00 & 13 Jan 2000 16:00 & 3 & WE_2000_01 & 2 & LE_2000_01 & 4 \\
\hline 13 Jan 2000 16:00 & 13 Jan 2000 17:30 & 1 & WE_2000_01 & 3 & LE_2000_01 & 4 \\
\hline 13 Jan 2000 17:30 & 14 Jan 2000 01:45 & 8 & WE_2000_01 & 4 & LE_2000_01 & 4 \\
\hline 14 Jan 2000 01:45 & 14 Jan 2000 06:00 & 4 & WE_2000_01 & 4 & & 1 \\
\hline 14 Jan 2000 06:00 & 14 Jan 2000 18:00 & 12 & WE_2000_01 & 2 & & 1 \\
\hline 14 Jan 2000 18:00 & 18 Mar 2000 07:30 & 1525 & & 1 & & 1 \\
\hline 18 Mar 2000 07:30 & 18 Mar 2000 12:30 & 5 & WE_2000_02 & 3 & & 1 \\
\hline 18 Mar 2000 12:30 & 18 Mar 2000 18:00 & 5 & WE_2000_02 & 3 & LE_2000_02 & 2 \\
\hline 18 Mar 2000 18:00 & 22 Nov 2000 10:00 & 5968 & & 1 & & 1 \\
\hline 22 Nov 2000 10:00 & 22 Nov 2000 11:00 & 1 & WE_2000_03 & 2 & & 1 \\
\hline 22 Nov 2000 11:00 & 22 Nov 2000 12:00 & 1 & WE_2000_03 & 2 & LE_2000_03 & 3 \\
\hline 22 Nov 2000 12:00 & 22 Nov 2000 17:00 & 5 & WE_2000_03 & 4 & LE_2000_03 & 3 \\
\hline 22 Nov 2000 17:00 & 23 Nov 2000 07:30 & 14 & WE_2000_03 & 4 & & 1 \\
\hline 23 Nov 2000 07:30 & 31 Dec 2000 23:59 & 928 & & 1 & & 1 \\
\hline
\end{tabular}

\begin{tabular}{|c|c|c|c|c|c|}
\hline \multirow{2}{*}{\multicolumn{2}{|c|}{$\begin{array}{l}\text { Alert } \\
\text { classification } \\
\text { criterion } \\
\text { (A) }\end{array}$}} & \multicolumn{4}{|c|}{ Landslide events } \\
\hline & & 1 (no) & 2 (S) & $3(1)$ & $4(\mathrm{~L})$ \\
\hline \multirow{4}{*}{ 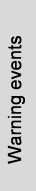 } & 1 (no) & $\mathrm{n} / \mathrm{a}$ & \multirow[b]{2}{*}{ TN } & \multirow{2}{*}{\multicolumn{2}{|c|}{ MA }} \\
\hline & $2(\mathrm{M})$ & & & & \\
\hline & $3(\mathrm{H})$ & \multirow{2}{*}{\multicolumn{2}{|c|}{ FA }} & \multirow{2}{*}{\multicolumn{2}{|c|}{$\mathrm{CA}$}} \\
\hline & $4(\mathrm{VH})$ & & & & \\
\hline
\end{tabular}

\begin{tabular}{|c|c|c|c|c|c|}
\hline \multirow{2}{*}{\multicolumn{2}{|c|}{$\begin{array}{l}\text { Grade of } \\
\text { correctness } \\
\text { criterion } \\
\text { (B) }\end{array}$}} & \multicolumn{4}{|c|}{ Landslide events } \\
\hline & & 1 (no) & 2 (S) & $3(1)$ & 4 (L) \\
\hline \multirow{4}{*}{ 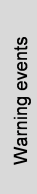 } & 1 (no) & $\mathrm{n} / \mathrm{a}$ & & & \\
\hline & $2(\mathrm{M})$ & & & & \\
\hline & $3(\mathrm{H})$ & & & & \\
\hline & $4(\mathrm{VH})$ & & & & \\
\hline
\end{tabular}
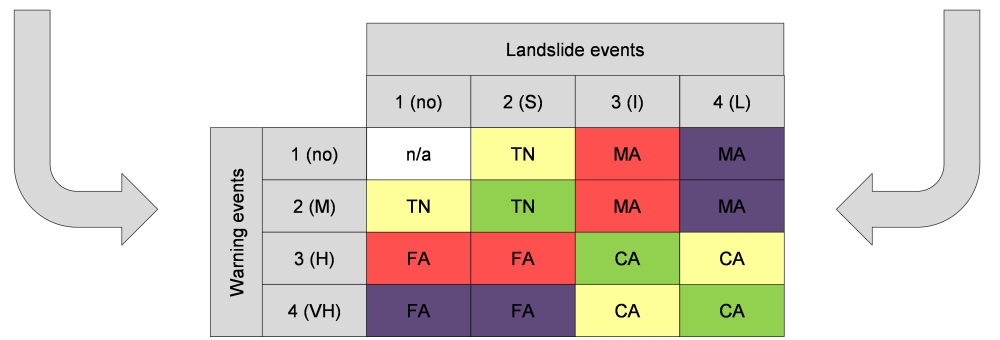

Figure 7. Examples of performance criteria which can be used for the analysis of the duration matrix: alert classification criterion (A) and grade of correctness criterion (B).

Table 7. Duration matrix: results using data from Table 6.

\begin{tabular}{llrccc}
\hline & & \multicolumn{4}{c}{ LE duration (h) } \\
\cline { 3 - 6 } & & $1(\mathrm{no})$ & $2(\mathrm{M})$ & $3(\mathrm{H})$ & $4(\mathrm{VH})$ \\
\hline WE & $1(\mathrm{no})$ & 8719 & 0 & 0 & 3 \\
duration & $2(\mathrm{M})$ & 13 & 0 & 1 & 3 \\
(h) & $3(\mathrm{H})$ & 5 & 5 & 0 & 1 \\
& $4(\mathrm{VH})$ & 18 & 0 & 5 & 8 \\
\hline
\end{tabular}

nabara and Zona Sul. Since 2010 the GEO-Rio foundation has been publishing information on landslide occurrences by means of yearly landslide reports (http://www0.rio.rj.gov.br/ alertario/) which comprise the time of occurrence, the main characteristics and the location of the recorded phenomena. The warnings database has been created from information directly gathered at the GEO-Rio Foundation. For the chosen period of analysis Calvello et al. (2015b) show that $72 \%$ of the recorded landslides occurred in Baia de Guanabara, where seven warning events reached a high or very high warning level, and $10 \%$ of the recorded landslides occurred 
Table 8. Performance indicators derived from the two performance criteria reported in Fig. 7 using data from duration matrix reported in Table 7.

\begin{tabular}{|c|c|c|c|c|}
\hline Performance indicator & $\begin{array}{l}\text { Performance } \\
\text { criterion }\end{array}$ & Symbol & Formula & Value \\
\hline Efficiency index & Criterion A & $I_{\mathrm{eff}}$ & $(\mathrm{CA}+\mathrm{TN}) / \Sigma_{i j} d_{i j}$ (excluding $\left.d_{11}\right)$ & 0.44 \\
\hline Hit rate & Criterion A & $\mathrm{HR}_{\mathrm{L}}$ & $\mathrm{CA} /(\mathrm{CA}+\mathrm{MA})$ & 0.67 \\
\hline Predictive power & Criterion A & $\mathrm{PP}_{\mathrm{W}}$ & $\mathrm{CA} /(\mathrm{CA}+\mathrm{FA})$ & 0.33 \\
\hline Threat score & Criterion A & TS & $\mathrm{CA} /(\mathrm{CA}+\mathrm{MA}+\mathrm{FA})$ & 0.29 \\
\hline Odds ratio & Criterion A & OR & $(\mathrm{CA}+\mathrm{TN}) /(\mathrm{MA}+\mathrm{FA})$ & 0.77 \\
\hline Misclassification rate & Criterion A & MR & $1-I_{\mathrm{eff}}$ & 0.56 \\
\hline Missed alert rate & Criterion A & $R_{\mathrm{MA}}$ & $1-\mathrm{HR}$ & 0.33 \\
\hline False alert rate & Criterion A & $R_{\mathrm{FA}}$ & $1-\mathrm{PP}$ & 0.67 \\
\hline Error rate & Criterion B & ER & $(\operatorname{Red}+\mathrm{Pur}) / \Sigma_{i j} d_{i j}\left(\right.$ excluding $\left.d_{11}\right)$ & 0.56 \\
\hline Probability of serious mistakes & Criterion B & $P_{\mathrm{SM}}$ & $\operatorname{Pur} / \Sigma_{i j} d_{i j}$ (excluding $d_{11}$ ) & 0.39 \\
\hline Probability of serious no-warning mistakes & Criterion B & $P_{\mathrm{SM}-\mathrm{NW}}$ & $\operatorname{Pur}_{i 4} / \Sigma_{i j} d_{i j}($ for $i=1, j=2-4)$ & 1 \\
\hline Probability of serious no-landslides mistakes & Criterion B & $P_{\mathrm{SM}-\mathrm{NL}}$ & $\operatorname{Pur}_{4 j} / \Sigma_{i j} d_{i j}($ for $i=2-4, j=1)$ & 0.5 \\
\hline Index of severity of missed alerts & Criteria A and B & $I_{\mathrm{MA}}$ & (Pur \& MA)/MA & 0.86 \\
\hline Index of severity of false alerts & Criteria A and B & $I_{\mathrm{FA}}$ & $($ Pur \& FA)/FA & 0.64 \\
\hline
\end{tabular}

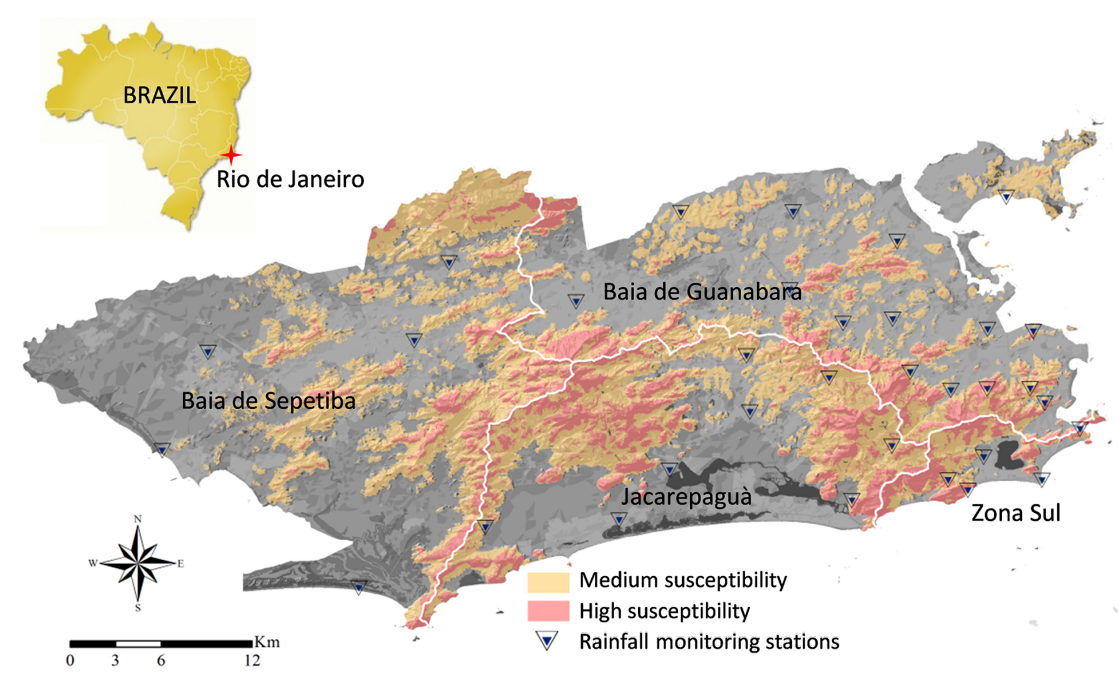

Figure 8. Subdivision of the Rio de Janeiro municipal territory for early warning purposes, susceptibility map and location of the rainfall monitoring stations.

in Zona Sul, where five warning events reached a high or very high warning level.

The parametric analysis conducted herein has a twofold purpose: to compare the performance of the Alerta Rio early warning model in two different alert zones of the city and to evaluate the effect of the choices the analyst needs to make to define LE and WE on the performance indicators computed according to the EDuMaP method within a given alert zone. To investigate the latter, the Baia de Guanabara alert zone was chosen.

Table 9 shows the values used for each simulation of the parametric analysis for the 10 input parameters needed to define the landslide and warning events. The values of the input parameters chosen for simulations ZS_T1 and G_T1, which refer to the two base cases for the alert zones Zona Sul and Baia de Guanabara, respectively, adequately represent the structure and the operative procedures of the warning model employed within Alerta Rio. For these two simulations, the following values of the 10 input parameters are used: area of analysis, $A$, equal to $\mathrm{ZS}$ and $\mathrm{G}$, respectively; warning levels, $W_{\text {lev }}$, equal to 4 ; landslide density, $L_{\mathrm{den}(k)}$, defined according to the mixed criterion shown in Table 3; lead time, $t_{\mathrm{LEAD}}$, equal to 0 ; landslide typology, $L_{\mathrm{typ}}$, equal to all recorded landslides; minimum interval between landslide events, $\Delta t_{\mathrm{LE}}$, equal to $12 \mathrm{~h}$; over time, $t_{\mathrm{OVER}}$, equal to 0 ; spatial discretization adopted for warnings, $\Delta A_{(k)}$, equal to the area of analysis $\mathrm{A}$; time frame of analysis, $\Delta T$, equal to the 3-year period 2010-2012; temporal discretization of 


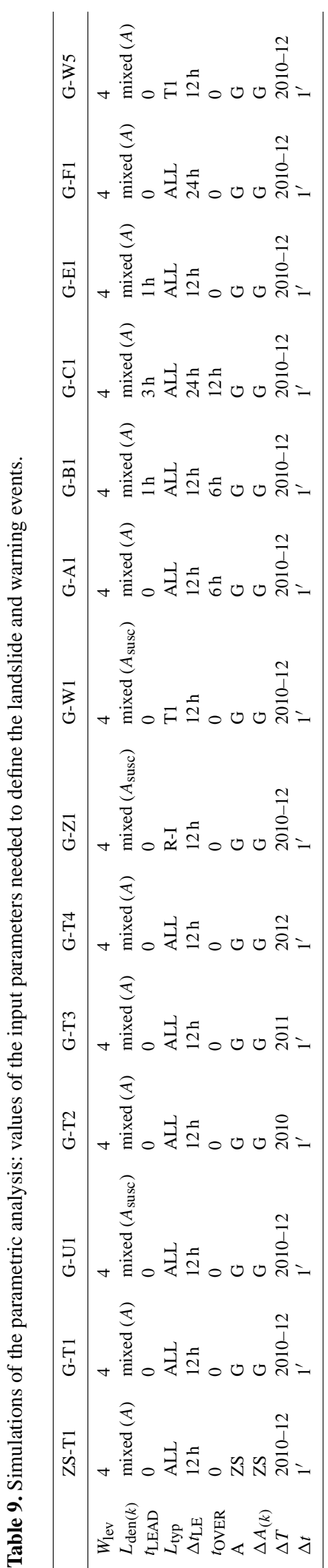

Table 10. Duration matrix of simulation ZS_T1.

\begin{tabular}{llrrrr}
\hline & & \multicolumn{4}{c}{ LE duration (h) } \\
\cline { 3 - 6 } & & $1(\mathrm{no})$ & $2(\mathrm{~S})$ & $3(\mathrm{I})$ & $4(\mathrm{~L})$ \\
\hline WE & $1(\mathrm{no})$ & 8185.1 & 19.1 & 20.4 & 0.0 \\
duration & $2(\mathrm{M})$ & 288.4 & 16.7 & 0.7 & 0.0 \\
(h) & $3(\mathrm{H})$ & 90.0 & 6.0 & 3.1 & 32.4 \\
& $4(\mathrm{VH})$ & 28.5 & 0.1 & 38.1 & 31.4 \\
\hline
\end{tabular}

Table 11. Duration matrix of simulation $\mathrm{G}_{-} \mathrm{T} 1$.

\begin{tabular}{llrccr}
\hline & & \multicolumn{4}{c}{ LE duration (h) } \\
\cline { 3 - 6 } & & $1(\mathrm{no})$ & $2(\mathrm{~S})$ & $3(\mathrm{I})$ & $4(\mathrm{~L})$ \\
\hline WE & $1(\mathrm{no})$ & 8281.8 & 0.4 & 0.0 & 0.0 \\
duration & $2(\mathrm{M})$ & 302.0 & 0.0 & 0.0 & 5.4 \\
(h) & $3(\mathrm{H})$ & 100.1 & 0.2 & 0.0 & 2.8 \\
& $4(\mathrm{VH})$ & 54.8 & 0.0 & 0.0 & 12.6 \\
\hline
\end{tabular}

analysis, $\Delta t$, equal to $1 \mathrm{~min}$. All the remaining simulations, from G-U01 to G-W05, refer to the alert zone Baia de Guanabara. These simulations are used to explore the sensitivity of the performance evaluation of the Alerta Rio regional warning model to changes in the input parameters, whose values differ, depending on choices made by the analyst, also under the same set of landslides and warnings data. To this purpose, the input parameters investigated are landslide density, $L_{\mathrm{den}(k)}$, defined according to the mixed criterion shown in Table 3 either in relation to the whole area of analysis $(A)$ or in relation to the extent of the area most susceptible to landslides $\left(A_{\text {susc }}\right)$; lead time, $t_{\text {LEAD }}$, varying from 0 to $3 \mathrm{~h}$; landslide typology, $L_{\text {typ }}$, equal to all recorded landslides (ALL), all typologies of landslides excluding rock falls (R-I) and earth slides in artificial slopes (T1); minimum interval between landslide events, $\Delta t_{\mathrm{LE}}$, equal to 12 and $24 \mathrm{~h}$; over time, $t_{\text {OVER }}$, varying from 0 to $12 \mathrm{~h}$; and time frame of analysis, $\Delta T$, equal to the whole 3-year period 2010-2012 or to the single years 2010, 2011 and 2012.

\subsection{Results of parametric analysis}

The duration matrices of Tables 10 and 11 report the results of the first two simulations of the parametric analysis, ZS_T1 and $\mathrm{G}_{-} \mathrm{T} 1$, which only differ in relation to the area of analysis, the Zona Sul and the Baia de Guanabara alert zones, respectively. Figures 9 and 10 show a comparison of the results of the first two simulations, ZS_T1 and G_T1. Considering performance criterion A, Zona Sul and Baia de Guanabara both present a high rate of TNs and a low rate of MAs. The low rate of computed MAs also turns into a good predicting capability in relation to intermediate and large landslide events occurring in these zones. Baia de Guanabara shows time values associated to CAs much higher than the corre- 


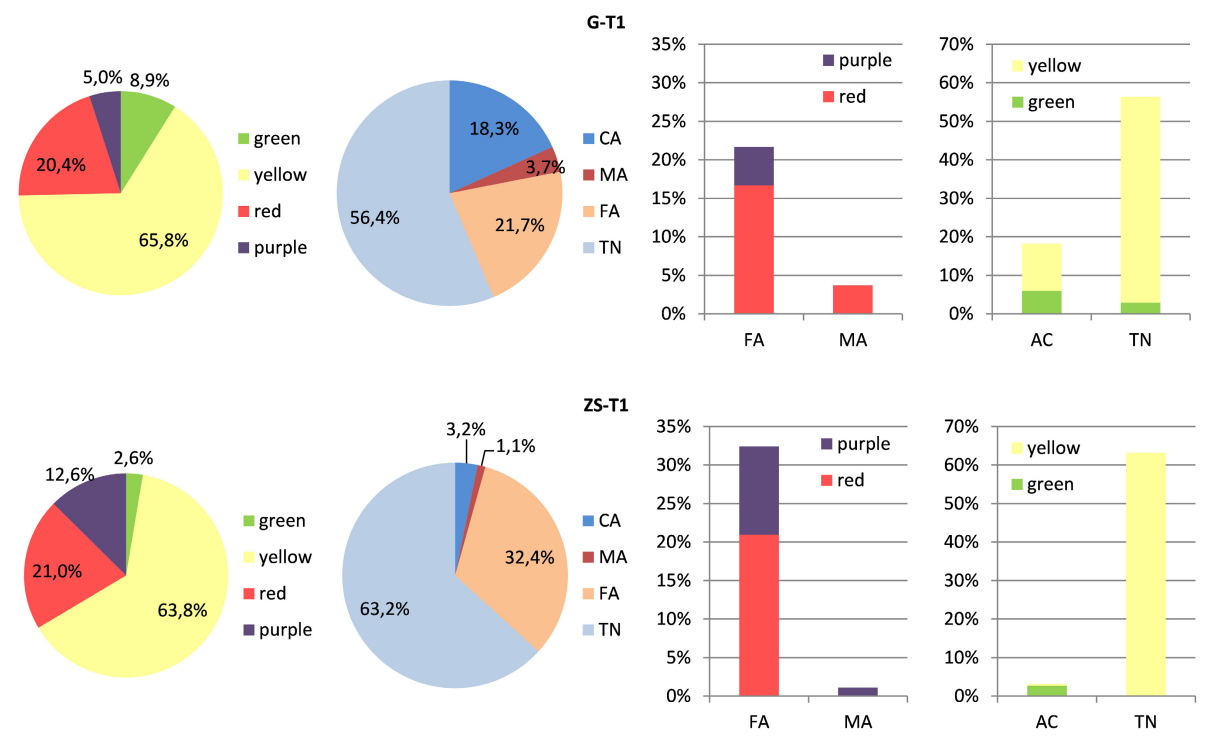

Figure 9. Simulations for the base cases of alert zones Guanabara (G-T1) and Zona Sul (ZS-T1): distribution of the elements of the duration matrix in terms of criterion A (correct alerts, CAs; missed alerts, MAs; false alerts, FAs; true negatives, TNs) and criterion B (color code following a grade of correctness from green to purple).
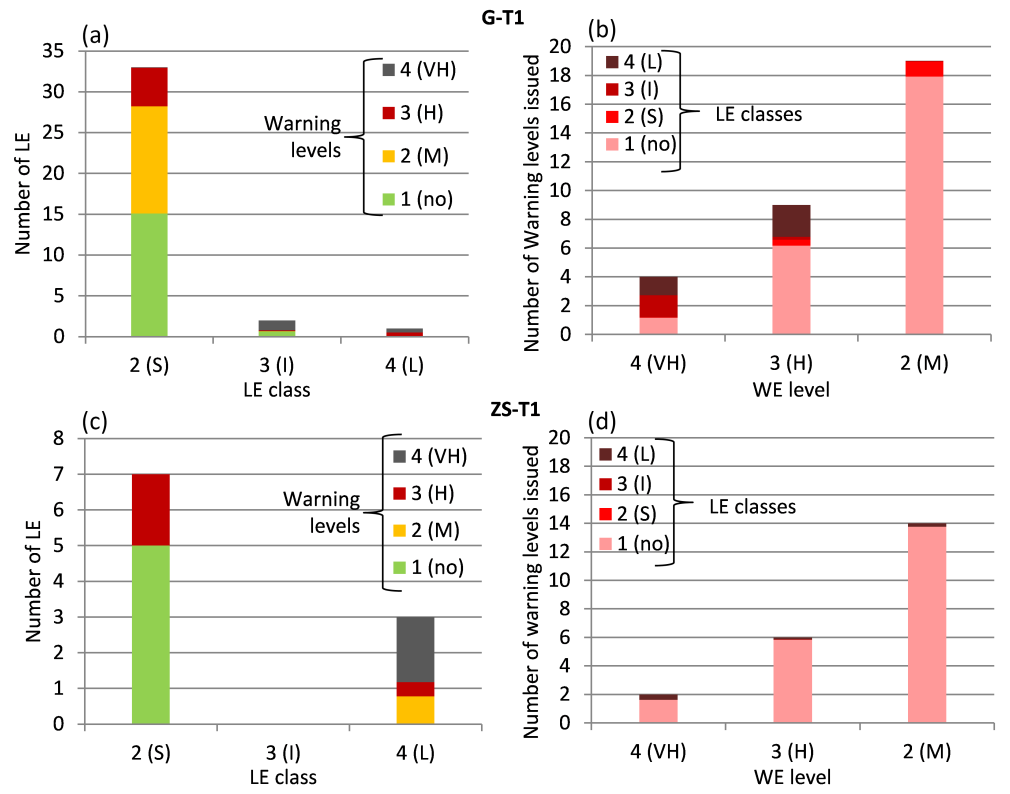

Figure 10. Simulations for the base cases of alert zones Guanabara (G-T1) and Zona Sul (ZS-T1). Number of landslide events (LE) and warning levels issued, normalized, respectively, in relation to (a, c) landslide events, d_LE $i j$ (Eq. 2), and (b, d) warning events (WE), d_WE $i j$ (Eq. 3).

sponding values in Zona Sul: $18.3 \%$ versus $3.2 \%$ of the total considered time. These differences justify the fact that the value of efficiency index ( $\left.I_{\text {eff }}\right)$ computed for Baia de Guanabara, $75 \%$, is higher than that computed for Zona Sul, $66 \%$; $R_{\mathrm{MA}}$ is also slightly higher for Zona Sul. The results for Zona Sul also highlight a relatively high rate of FAs (32\%), probably due to values of rainfall thresholds inadequately low for this alert zone. This condition, together with a low value of
CAs, explains the high value of the missed alert rate $(91 \%)$ for Zona Sul. Considering performance criterion B, approximately the same time rate of yellow elements (minor model errors) and red elements (significant model errors) are observed for the two alert zones. Significant is, however, the difference in the time rate of purple elements (worst model errors), which is much higher for Zona Sul than for Baia de Guanabara. It is interesting to notice that Zona Sul has a low 

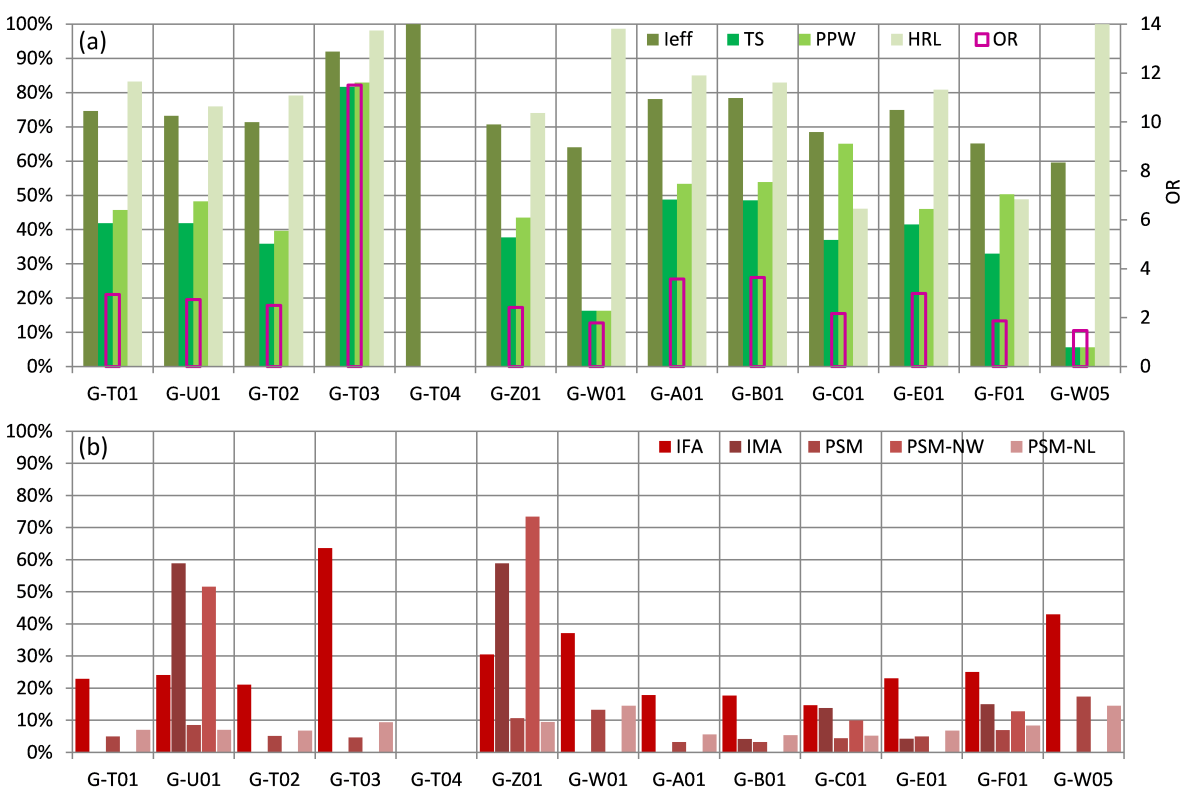

Figure 11. Simulations for different cases of alert zone Guanabara, G_T1 to G_W5 (see Table 9 for the input parameters used for the events analysis): values of performance indicators related to the success (a) and to the errors (b) of the warning model.
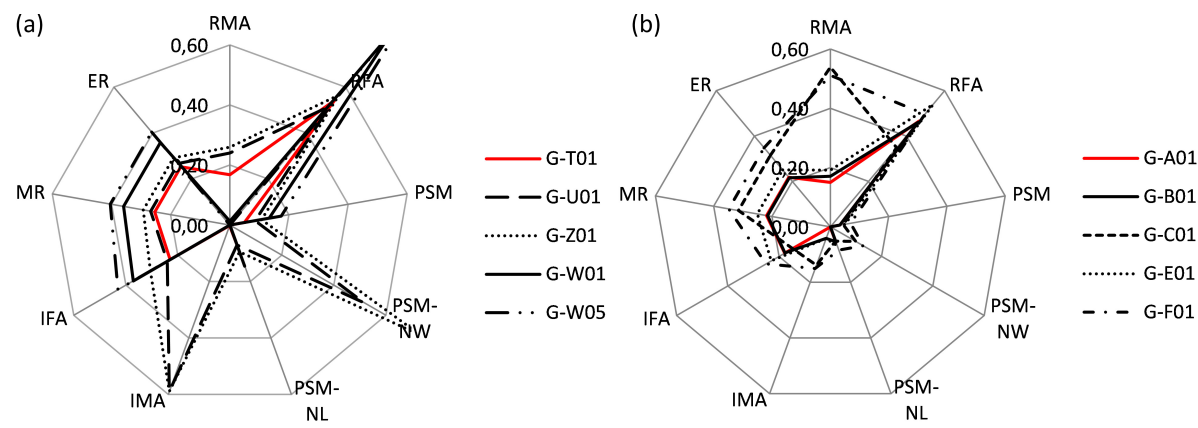

Figure 12. Simulations for different cases of alert zone Guanabara, G_T1 to G_W5 (see Table 9 for the input parameters used for the events analysis): values of all the performance indicators related to errors of the warning model, grouped to highlight the effect of parameters $L_{\text {den }(k)}$, and $L_{\text {typ }}\left(\right.$ a) and parameters $\Delta t_{\text {LE }}, t_{\text {LEAD }}$ and $t_{\text {OVER }}(\mathbf{b})$.

rate of MAs, yet $I_{\mathrm{MA}}$ is equal to 1 because the only value of MA is a serious model error. Finally, slightly high values are computed for Zona Sul for the probability of serious mistakes $\left(P_{\mathrm{SM}}\right)$, probability of serious no-warning mistakes $\left(P_{\mathrm{SM}-\mathrm{NW}}\right)$ and probability of serious no-landslides mistakes $\left(P_{\mathrm{SM}-\mathrm{NL}}\right)$.

Simulations G_T1 to G_W5 refer to the alert zone Baia de Guanabara and may thus be used to explore the sensitivity of the performance evaluation to the changes in the values of the other input parameters (Table 12, Figs. 11 and 12). The simulations addressing the parameters landslide density, $L_{\mathrm{den}(k)}$, and landslide typology, $L_{\mathrm{typ}}$, are the following: G_T1, G_U1, G_Z1, G_W1 and G_W5. The definition of the landslide density parameter, $L_{\operatorname{den}(k)}$, in relation to the whole area of analysis $(A)$ or in relation to the extent of the area most susceptible to landslides $\left(A_{\text {susc }}\right)$ does not play an impor- tant role for some performance indicators (e.g., $\mathrm{EI}_{(\mathrm{A})}, \mathrm{GC}_{(\mathrm{B})}$, $\mathrm{PP}_{\mathrm{W}}, \mathrm{HR}, \mathrm{OR}, \mathrm{R}_{\mathrm{FA}}$ ) while it may be very relevant for others (e.g., $P_{\mathrm{SM}-\mathrm{NW}}, P_{\mathrm{SM}-\mathrm{NL}}, I_{\mathrm{MA}}$ ) (Table 12). The area considered when computing this parameter has, indeed, a strong influence on the number of landslides set as thresholds to differentiate among classes of landslide events. In particular, when the area reduces, the threshold values decrease and, other parameters being equal, the number of very large and large landslide events tends to increase. The latter implies an increasing probability of MAs and of the worst model errors (Pur) in this region of the matrix. For instance, the fact that simulation G_U1 shows high values of $P_{\mathrm{SM}-\mathrm{NW}}$ and $I_{\mathrm{MA}}$ (Table 12) depends on a single missed landslide event classified as class 4 (L), differently from the classification 3 (I) resulting from the base simulation $G_{-}$T1. As far as landslide typology is concerned, the results from the two combinations 
Table 12. Values of the performance indicators for all the simulations of the parametric analysis.

\begin{tabular}{|c|c|c|c|c|c|c|c|c|c|c|c|c|c|c|}
\hline $\begin{array}{l}\text { Performance } \\
\text { indicator }\end{array}$ & ZS-T1 & G-T1 & G-U1 & G-T2 & G-T3 & G-T4 & G-Z1 & G-W1 & G-A1 & G-B1 & G-C1 & G-E1 & G-F1 & G-W5 \\
\hline$I_{\text {eff }}$ & 0.66 & 0.75 & 0.73 & 0.71 & 0.92 & 1.00 & 0.71 & 0.64 & 0.78 & 0.78 & 0.68 & 0.75 & 0.65 & 0.60 \\
\hline $\mathrm{PP}_{\mathrm{W}}$ & 0.09 & 0.46 & 0.48 & 0.40 & 0.83 & 0.00 & 0.43 & 0.16 & 0.53 & 0.54 & 0.65 & 0.46 & 0.50 & 0.06 \\
\hline TS & 0.09 & 0.42 & 0.42 & 0.36 & 0.82 & 0.00 & 0.38 & 0.16 & 0.49 & 0.49 & 0.37 & 0.42 & 0.33 & 0.06 \\
\hline OR & 1.98 & 2.95 & 2.74 & 2.50 & 11.51 & 0.00 & 2.42 & 1.78 & 3.58 & 3.64 & 2.17 & 2.99 & 1.87 & 1.47 \\
\hline$R_{\mathrm{FA}}$ & 0.91 & 0.54 & 0.52 & 0.60 & 0.17 & 0.00 & 0.57 & 0.84 & 0.47 & 0.46 & 0.35 & 0.54 & 0.50 & 0.94 \\
\hline ER & 0.34 & 0.25 & 0.27 & 0.29 & 0.08 & 0.00 & 0.29 & 0.36 & 0.22 & 0.22 & 0.32 & 0.25 & 0.35 & 0.40 \\
\hline$P_{\mathrm{SM}}$ & 0.13 & 0.05 & 0.09 & 0.05 & 0.05 & 0.00 & 0.11 & 0.13 & 0.03 & 0.03 & 0.04 & 0.05 & 0.07 & 0.17 \\
\hline$P_{\mathrm{SM}-\mathrm{NW}}$ & 0.00 & 0.00 & 0.52 & 0.00 & 0.00 & 0.00 & 0.73 & 0.00 & 0.00 & 0.00 & 0.10 & 0.00 & 0.13 & 0.00 \\
\hline$P_{\mathrm{SM}-\mathrm{NL}}$ & 0.12 & 0.07 & 0.07 & 0.07 & 0.09 & 0.00 & 0.09 & 0.15 & 0.06 & 0.05 & 0.05 & 0.07 & 0.08 & 0.15 \\
\hline
\end{tabular}

associated only to the occurrence of earth slides on artificial slopes (G_W1 and G_W5) are similar and show $I_{\text {eff(A) }}$ less than $70 \%$, HR around $100 \%$, very few MAs, around $35 \%$ of FAs and $I_{\mathrm{FA}}$ values much higher than the rest of the simulations (Table 12). Probably the latter is due to two concurrent factors: threshold values which are set too low for this landslide typology and lower average duration of the landslide events due to the reduced number of landslides compared to the other simulations. Concerning the three parameters lead time, $t_{\mathrm{LEAD}}$, over time, $t_{\mathrm{OVER}}$, and minimum interval between landslide events, $\Delta t_{\mathrm{LE}}$, the simulations relevant to explore their importance are the following: $G_{-} T 1, G_{-} A 1$, G_B1, G_C1, G_E1 and G_F1. High values of $\Delta t_{\mathrm{LE}}$ considerably increase the values of the performance indicators related to the rate of MAs ( $R_{\mathrm{MA}}, \mathrm{ER}, \mathrm{MR}, P_{\mathrm{SM}-\mathrm{NW}}$ ), while the rate of FAs does not change significantly. This is due to the fact that the higher the value of $\Delta t_{\mathrm{LE}}$ is, the lower the number of landslide events, the higher the duration of each landslide event and the higher the chance to have time periods associated to landslide events without warning events. These results seem to indicate that an appropriate performance evaluation needs parameter $\Delta t_{\mathrm{LE}}$ to be set, by the analyst, to a value lower than $24 \mathrm{~h}$. The comparison of results for G_T1 and $\mathrm{G} \_\mathrm{A} 1$ shows that the introduction of a $t_{\mathrm{OVER}}$ of $6 \mathrm{~h}$ increases the performance by reducing the FAs and increasing the CAs. Consequently $I_{\mathrm{FA}}$ and $R_{\mathrm{MA}}$ slightly decrease compared to the case G_T1 (Table 12), for which $t_{\text {OVER }}$ is equal

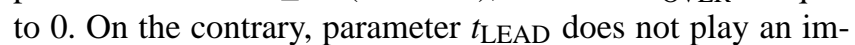
portant role for this analysis. Finally, the simulations which are relevant to explore the importance of the time frame of analysis, $\Delta T$, are the followings: G_T1, G_T2, G_T3 and G_T4. The resulting values of the performance indicators from these simulations highlight the importance played by the data set used for the performance analysis. Indeed, the inconsistency between the results of the two simulations which consider the single years 2011 and 2012 (G_T3 and G_T4) and the rest of the simulations may be ascribed to the very limited amount of data available for those years, for which very few landslides occurred and very few warnings were issued.

\section{Conclusions}

A regional landslide early warning system may be schematized as a system with the following components: regional warning model, monitoring and warning strategy, communication strategy and emergency plan. The focus of this article was on the performance evaluation of regional warning models for rainfall-induced landslides, that is to say on the effectiveness of the functional relationship between rainfall events and landslide events used within the decision-making procedures adopted to issue the warnings. It is import to highlight that the proposed performance assessment method does not address other important issues related to system effectiveness, such as risk perception, policy adopted to communicate with the people at risk, evacuation procedures, monitoring network and instruments used to issue the warnings.

The proposed approach, which has been called EDuMaP method, evaluates the performance of a regional landslide warning model following three successive steps: (1) identification and analysis of landslide events and warning events derived from available landslides and warnings databases, (2) definition and computation of a duration matrix reporting the time associated with the occurrence of landslide events in relation to the occurrence of warning events and (3) evaluation of the model performance by means of criteria and indicators applied to the duration matrix.

The main innovations introduced by the EDuMaP method, in relation to means more commonly used to assess the performance of such models, are the following: 
- recorded landslides and issued warnings are not analyzed as a series of individual occurrences but they are grouped within landslide and warning events, respectively, which consider their spatial and temporal characteristics by means of 10 input parameters;

- the evaluation of the correlation between landslide and warning events is based not on counting the pairs on which the two data sets agree or disagree but rather on computing the duration of the agreement/disagreement;

- the correspondence between landslide and warning events is expressed not as a 2 by 2 confusion matrix but as a matrix, herein called duration matrix, whose number of columns and rows depends on the schemes adopted to classify, respectively, landslide events and warning events;

- the assessment of the duration matrix is based on performance indicators derived from a set of performance criteria, which must be defined by the system analyst/manager considering the specific characteristics and aims of the early warning system under evaluation.

Concerning the latter issue, two performance criteria have been used herein. The first criterion is defined in accordance to a standard alert classification scheme derived from a 2 by 2 contingency table, thus identifying correct alerts, false alerts, missed alerts and true negatives. The second criterion is defined by assigning a color code to the elements of matrix, from green to purple, in relation to their grade of correctness. Both criteria purposefully neglect the duration matrix element $d_{11}$, whose value is typically orders of magnitude higher than the values of the other elements. Other criteria could be used to assess the results of a duration matrix. It is important to highlight, however, that a reasonable performance criterion should keep the latter assumption. Indeed, if a criterion does consider the value of the element $d_{11}$, the resulting performance indicators would be positively "biased" for obvious reasons (i.e., rainfall-induced landslides do not occur when it does not rain).

The applicability of the EDuMaP method has been tested by conducting a parametric analysis using 3 years of landslides and warnings data from the municipal landslide early warning system operating in Rio de Janeiro (Brazil). The input parameters most affecting the results of the events analysis and, thus, the value of the elements of duration matrix for the different simulations, are as follows: the landslide density thresholds used to differentiate among the classes of landslide events, the set of landslides considered in the simulations, the time set as the minimum time interval between landslide events, the time interval between the last landslide identified within a landslide event and the assumed ending of the landslide event, the area of analysis and the time frame of the analysis. For instance, the criterion herein employed to define landslide density does not work well when the number of landslides per unit area is computed using the area mapped as the most susceptible instead of the whole area of analysis. The latter does not mean that a higher number of landslides occurs outside the most susceptible area; it only means that the thresholds used in the criterion more adequately represent a landslide density computed over the whole alert zone. Another parameter to which the results are very sensitive is the time interval used to identify the number of landslides to include within a single landslide event. When this period becomes too long (equal to or higher than $24 \mathrm{~h}$ ), the duration of some landslide events increases too much, and thus some time intervals are misleadingly accounted for as serious missed alerts. Finally, as expected, the performance assessment has proved to be very sensitive to the number of data used, mainly function of the two parameters defining the type of landslides and the time frame of the analysis. Of course, the results of the performed analysis cannot be easily generalized. This is true for a number of reasons: they have to be considered specific of the warning model adopted by the Rio de Janeiro early warning system; not all the input parameters were tested in the parametric analysis; the time for which both landslides and warnings data are available is relatively short.

In conclusion, the EDuMaP method proved its applicability to a real case study, by means of a sensitivity analysis which also gave some preliminary indications on the relative importance of the input parameters needed to apply it. The EDuMaP method is proposed to be used for the performance evaluation of any regional landslide early warning systems for which landslides and warnings data are available. Moreover, given its characteristics, it may also be easily adapted to evaluate the efficiency of regional early warning models addressing other natural hazards.

Acknowledgements. The authors thank the GPE staff of the GEORio Foundation in Rio de Janeiro and Ricardo d'Orsi for their kindness in sharing the databases used and their availability to share information about the Alerta Rio early warning system.

The work described in this paper was financially supported by the $\mathrm{PhD}$ programme of the civil engineering department at the University of Salerno and by the Project of National Relevance (PRIN) "Landslide risk mitigation through sustainable countermeasures", funded by the Italian Ministry of Education (MIUR).

Edited by: T. Glade

Reviewed by: two anonymous referees

\section{References}

Aleotti, P.: A warning system for rainfall-induced shallow failures, Eng. Geol., 73, 247-265, 2004.

Baum, R. L. and Godt, J. W.: Early warning of rainfall-induced shallow landslides and debris flows in the USA, Landslides, 7, 259272, 2010. 
Bell, R., Thiebes, B., Glade, T., Vinogradov, R., Kuhlmann, H., Schauerte, W., Burghaus, S., Krummel, H., Janik, M., and Paulsen, H.: The technical concept within the Integrative Landslide Early Warning System (ILEWS), landslides and engineered slopes, from the past to the future, in: Proceedings of the 10th International Symposium on Landslides and Engineered Slopes, 30 June-4 July 2008, Xi' an, China, 1083-1088, 2008.

Berti, M., Martina, M. L. V., Franceschini, S., Pignone, A., Simoni, A., and Pizziolo, M.: Probabilistic rainfall thresholds for landslide occurrence using a Bayesian approach, J. Geophys. Res., 117, F04006, doi:10.1029/2012JF002367, 2012.

Blikra, L. H.: The Åknes rockslide: monitoring, threshold values and early-warning, in: Landslides and Engineered Slopes, edited by: Chen, Z., Zhang, J. M., Ho, K., Wu, F. Q., and Li, Z. K., Taylor \& Francis Group, London, 1089-1094, 2008.

Calvello, M., d'Orsi, R., Piciullo, L., Paes, N. M., Magalhaes, M. A., Coelho, R., and Lacerda, W. A.: The community-based alert and alarm system for rainfall induced landslides in Rio de Janeiro, Brazil, in: Engineering Geology for Society and Territory "Landslide Processes", Proc. XII Int. IAEG Congress, Torino, Italy, 2, 653-657, doi:10.1007/978-3-319-09057-3_109, 2015a.

Calvello, M., d'Orsi, R. N., Piciullo, L., Paes, N., Magalhaes, M., and Lacerda, W. A.: The Rio de Janeiro early warning system for rainfall-induced landslides: analysis of performance for the years 2010-2013, Int. J. Disast. Risk Reduc., 12, 3-15, 2015 b.

Cannon, S., Boldt, E., Laber, J., Kean, J., and Staley, D.: Rainfall intensity-duration thresholds for postfire debris-flow emergency response planning, Nat. Hazards, 59, 209-236, 2011.

Capparelli, G. and Tiranti, D.: Application of the MoniFLaIR early warning system for rainfall induced landslides in Piedmont region (Italy), Landslides, 7, 401-410, 2010.

Chan, R. K. S. and Pun, W. K.: Landslip warning system in Hong Kong, Geotec. Instrum. News, 22, 33-35, 2004.

Cheung, P. Y., Wong, M. C., and Yeung, H. Y.: Application of rainstorm nowcast to real-time warning of landslide hazards in Hong Kong, in: WMO PWS, Workshop on Warnings of Real-Time Hazards by Using Nowcasting Technology, 9-13 October 2006, Sydney, Australia, 2006.

Chleborad, A. F.: A Method for Anticipating the Occurrence of Precipitation induced Landslides in Seattle, Washington, US Geological Survey, Open-File Report 00-469, US Geological Survey, Denver, USA, 29 pp., 2000.

Chleborad, A. F., Baum, R. L., and Godt, J. W.: A prototype system for forecasting landslides in the Seattle, Washington, Area. in: Engineering Geology and Landslides of the Seattle, Washington, Area: Geological Society of America Reviews in Engineering Geology, edited by: Highland, L. M., Baum, R. L., and Godt, J. W., Geological Society of America, Boulder, 103-120, 2008.

Coelho Netto, A. L., Avelar, A. S., Fernandes, M. C., and Lacerda, W. A.: Landslide susceptibility in a mountainous geoecosystem, Tijuca Massif, Rio de Janeiro: The role of morphometric subdivision of the terrain, Geomorphology, 87, 120-131, doi:10.1016/j.geomorph.2006.03.041, 2007.

Devoli, G., Ingeborg, K., Monica, S., Nils-Kristian, O., Ragnar, E., Erik, J., and Hervé, C.: Landslide early warning system and web tools for real-time scenarios and for distribution of warning messages in Norway, in: Engineering Geology for Society and Territory "Landslide Processes", Proc. XII Int. IAEG Congress,
Torino, Italy, 625-629, doi:10.1007/978-3-319-09057-3_104, 2015.

DGR: n. 2312 del 27/12/2007, Deliberazione di Giunta Regionale dell'Umbria: Disposizioni in attuazione dell'art, 3 bis della Legge 100/2012 e della Direttiva del Presidente del Consiglio dei Ministri del 27.02.2004 - Sistema di Allertamento Regionale e Centro Funzionale Regionale, Umbria, Italy, 2007.

DGR: n. 895 del 29/18/2013, Deliberazione di Giunta Regionale della Toscana: Sistema di Allertamento Regionale e Centro Funzionale Regionale, Bollettino ufficiale della regione Toscana, n. 46 del 13/11/2013, Toscana, Italy, 2013.

DGR: n. 395 del 7/04/2015, Deliberazione di Giunta Regionale della Toscana: Sistema di Allertamento Regionale e Centro Funzionale Regionale, Bollettino ufficiale della regione Toscana, n. 15 del 15/4/2015, Toscana, Italy, 2015.

Di Biagio, E. and Kjekstad, O.: Early Warning, Instrumentation and Monitoring Landslides, in: Proceedings of the 2nd Regional Training Course, RECLAIM II, 29 January-2 February 2007, Phuket, Thailand, 2007.

d'Orsi, R. N.: Landslide risk reduction measures by the Rio de Janeiro city government, in: Improving the Assessment of Disaster Risks to Strengthen Financial Resilience, Special Joint G20 Publication, Government of Mexico and World Bank, 77-91, available at: http://www.preventionweb.net/ english/professional/publications/v.php?id=29011 (last access: 6 October 2015), 2012.

d'Orsi, R. N., D'Avila, C., Ortigao, J. A. R., Moraes, L., and Santos, M. D.: Rio-Watch: the Rio de Janeiro landslide watch, in: Proceedings of the 2nd PSL Pan-Am Symposium on Landslides, Rio de Janeiro, Brazil, 21-30, 1997.

d'Orsi, R. N., Feijó, R. L., and Paes, N. M.: 2,500 Operational days of Alerta Rio system: history and technical improvements of Rio de Janeiro warning system for severe weather, in: Landslides: Evaluation and Stabilization, edited by: Lacerda, W. A., Ehrlich, M., Fontoura, S. A. B., and Sayao, A. S. F., Taylor \& Francis Group, London, 831-836, 2004.

DPCM: 27/02/2004, Direttiva Presidente Consiglio dei Ministri: Indirizzi operativi per la gestione operativa e funzionale del sistema di allertamento nazionale, statale e regionale per il rischio idrogeologico ed idraulico ai fini di protezione civile, in: Gazzetta Ufficiale n. 59 del 11/03/2004, Roma, Italy, 2004.

DPGR: n. 299 del 30/06/2005, Decreto del Presidente della Giunta Regionale della Campania: Il Sistema di Allertamento Regionale per il rischio Idrogeologico e Idraulico ai fini di protezione civile, Bollettino ufficiale della regione Campania, n. speciale 01/08/2005, Campania, Italy, 2005.

DPRS: n. 626/GAB del 30/10/2014, Direttiva del Presidente della Regione Siciliana: Competenze, struttura organizzativa e procedure di allertamento del Centro Funzionale Decentrato Multirischio Integrato della Regione Siciliana - Settore IDRO, Sicilia, Italy, 2014.

Fell, R., Ho, K. K. S., Lacasse, S., and Leroi, E.: A framework for landslide risk assessment and management, in: Landslide Risk Management, edited by: Hungr, O., Fell, R., Couture, R., and Eberhardt, E., Taylor and Francis, London, 3-26, 2005.

Gariano, S. L., Brunetti, M. T., Iovine, G., Melillo, M., Peruccacci, S., Terranova, O., Vennari, C., and Guzzetti, F.: Calibration and validation of rainfall thresholds for shallow landslide forecasting in Sicily, southern Italy, Geomorphology, 228, 653-665, 2015. 
Glade, T. and Nadim, F.: Early warning systems for natural hazards and risks, Nat. Hazards, 70, 1669-1671, 2014.

Godt, J. W., Baum, R. L., and Chleborad, A. F.: Rainfall characteristics for shallow landsliding in Seattle, Washington, USA, Earth Surf. Proc. Land., 31, 97-110, 2006.

Greco, R., Giorgio, M., Capparelli, G., and Versace, P.: Early warning of rainfall-induced landslides based on empirical mobility function predictor, Eng. Geol., 153, 68-79, 2013.

Guzzetti, F., Peruccacci, S., Rossi, M., and Stark, C. P.: Rainfall thresholds for the initiation of landslides in central and southern Europe, Meteorol. Atmos. Phys., 98, 239-67, 2007.

Hyogo Framework for Action 2005-2015: Building the Resilience of Nations and Communities to Disasters, World Conference on Disaster Reduction 18-22 January 2005, Kobe, Hyogo, Japan, 22 pp., 2005.

International Centre of Geohazards: Guidelines for landslide monitoring and early warning systems in Europe - design and required technology, in: Project SafeLand "Living With Landslide Risk in Europe: Assessment, Effects of Global Change, and Risk Management Strategies", D4.8, http://www.safeland-fp7.eu (last access: April 2015), 2012.

Intrieri, E., Gigli, G., Mugnai, F., Fanti, R., and Casagli, N.: Design and implementation of a landslide early warning system, Eng. Geol., 147/148, 124-136, 2012.

Intrieri, E., Gigli, G., Casagli, N., and Nadim, F.: Brief communication "Landslide Early Warning System: toolbox and general concepts", Nat. Hazards Earth Syst. Sci., 13, 85-90, doi:10.5194/nhess-13-85-2013, 2013.

Keefer, D. K., Wilson, R. C., Mark, R. K., Brabb, E. E., Brown III, W. M., Ellen, S. D., Harp, E. L., Wieczoreck, G. F., Alger, C. S., and Zatkin, R. S.: Real-time landslide warning during heavy rainfall, Science, 238, 921-926, 1987.

Kirschbaum, D. B., Adler, R., Hong, Y., Kumar, S., Peters-Lidard, C., and Lerner-Lam, A.: Advances in landslide nowcasting: evaluation of a global and regional modeling approach, Environ. Earth Sci., 66, 1683-1696, doi:10.1007/s12665-011-0990-3, 2012.

Lagomarsino, D., Segoni, S., Fanti, R., and Catani, F.: Updating and tuning a regional-scale landslide early warning system, Landslides, 10, 91-97, 2013.

Lagomarsino, D., Segoni, S., Rosi, A., Rossi, G., Battistini, A., Catani, F., and Casagli, N.: Quantitative comparison between two different methodologies to define rainfall thresholds for landslide forecasting, Nat. Hazards Earth Syst. Sci., 15, 2413-2423, doi:10.5194/nhess-15-2413-2015, 2015.

Lollino, G., Arattano, M., and Cuccureddu, M.: The use of the automatic inclinometric system for landslide early warning: the case of Cabella Ligure (North-Western Italy), Phys. Chem. Earth, 27, 1545-1550, 2002.

Martelloni, G., Segoni, S., Fanti, R., and Catani, F.: Rainfall thresholds for the forecasting of landslide occurrence at regional scale, Landslides, 9, 485-495, 2012.

Maskrey, A.: Report on National and Local Capabilities for Early Warning, IDNDR Early Warning Programme, available at: http://www.unisdr.org/2006/ppew/whats-ew/pdf/ national-and-local-capabilities-ew-maskrey.pdf last access: 15 July 2015, IDNDR Secretariat, Geneva, 33 pp., 1997.

Michoud, C., Bazin, S., Blikra, L. H., Derron, M.-H., and Jaboyedoff, M.: Experiences from site-specific landslide early warn- ing systems, Nat. Hazards Earth Syst. Sci., 13, 2659-2673, doi:10.5194/nhess-13-2659-2013, 2013.

NOAA-USGS Debris Flow Task Force: NOAA-USGS Debris-Flow Warning System, Final report, US Geological Survey Circular 1283, available at: http://pubs.usgs.gov/circ/2005/1283/pdf/ Circular1283.pdf, last access: November 2014, US Geological Survey, Reston, Virginia, USA, 47 pp., 2005.

Osanai, N., Shimizu, T., Kuramoto, K., Kojima, S., and Noro, T.: Japanese early-warning for debris flows and slope failures using rainfall indices with Radial Basis Function Network, Landslides, 7, 325-338, 2010

Peres, D. J. and Cancelliere, A.: Development of rainfall thresholds for landslide early warning in Sicily: a method based on the use of rainfall annual maxima series, Rend. Online Soc. Geol. It., 21, 580-582, 2012.

Restrepo, P., Jorgensen, D. P., Cannon, S. H., Costa, J., Laber, J., Major, J., Martner, B., Purpura, J., and Werner, K.: Joint NOAA/NWS/USGS prototype debris flow warning system for recently burned areas in southern California, B. Am. Meteorol. Soc., 89, 1845, doi:10.1175/2008BAMS2416.1, 2008.

Rossi, M., Peruccacci, S., Brunetti, M. T., Marchesini, I., Luciani, S., Ardizzone, F., Balducci, V., Bianchi, C., Cardinali, M., Fiorucci, F., Mondini, A. C., Reichenbach, P., Salvati, P., Santangelo, M., Bartolini, D., Gariano, S. L., Palladino, M., Vessia, G., Viero, A., Antronico, L., Borselli, L., Deganutti, A. M., Iovine, G., Luino, F., Parise, M., Polemio, M., and Guzzetti, F.: SANF: National warning system for rainfall-induced landslides in Italy, in: Landslides and Engineered Slopes: Protecting Society through Improved Understanding, edited by: Eberhardt, E., Froese, C., Turner, K., and Leroueil, S., Taylor \& Francis, London, 1895-1899, 2012.

Segoni, S., Rossi, G., Rosi, A., and Catani, F.: Landslides triggered by rainfall: a semiautomated procedure to define consistent intensity-duration thresholds, Comput. Geosci., 3063, 123-131, 2014.

Segoni, S., Battistini, A., Rossi, G., Rosi, A., Lagomarsino, D., Catani, F., Moretti, S., and Casagli, N.: Technical Note: An operational landslide early warning system at regional scale based on space-time-variable rainfall thresholds, Nat. Hazards Earth Syst Sci., 15, 853-861, doi:10.5194/nhess-15-853-2015, 2015.

Stähli, M., Sättele, M., Huggel, C., McArdell, B. W., Lehmann, P., Van Herwijnen, A., Berne, A., Schleiss, M., Ferrari, A., Kos, A., Or, D., and Springman, S. M.: Monitoring and prediction in early warning systems for rapid mass movements, Nat. Hazards Earth Syst. Sci., 15, 905-917, doi:10.5194/nhess-15-905-2015, 2015.

Staley, D. M., Kean, J. W., Cannon, S. H., Schmidt, K. M., and Laber, J. L.: Objective definition of rainfall intensity-duration thresholds for the initiation of post-fire debris flows in southern California, Landslides, 10, 547-562, doi:10.1007/s10346-0120341-9, 2013.

Thiebes, B., Glade, T., and Bell, R.: Landslide analysis and integrative early warning-local and regional case studies, in: Landslides and Engineered Slopes: Protecting Society through Improved Understanding, edited by: Eberhardt, E., Taylor \& Francis Group, London, 1915-1921, 2012.

Thiebes, B., Bell, R., Glade, T., Jäger, S., Mayer, J., Anderson, M., and Holcombe, L.: Integration of a limit-equilibrium model into a landslide early warning system, Landslides, 11, 859-875, doi:10.1007/s10346-013-0416-2, 2013a. 
Thiebes, B., Glade, T., and Bell, R.: Landslide analysis and integrative early warning local and regional case studies, in: Landslides and Engineered Slopes, edited by: Eberhardt, E., Froese, C. R., Turner, A. K., and Leroueil, S., Taylor \& Francis Group, London, 1915-1921, 2013b.

Tiranti, D. and Rabuetti, D.: Estimation of rainfall thresholds triggering shallow landslides for an operational warning system implementation, Landslides, 7, 471-481, 2010.

Villagrán de León, J. C., Pruessner, I., and Breedlove, H.: Alert and Warning Frameworks in the Context of Early Warning Systems, a Comparative Review, Intersections No. 12, United Nations University Institute for Environment and Human Security, Bonn, 2013
Wilson, R. C.: The rise and fall of a debris-flow warning system for the San Francisco Bay Region, California, in: Landslide Hazard and Risk, edited by: Glade, T., Anderson, M., and Crozier, M. J., Wiley, New York, 493-516, 2004.

Yu, Y. F., Lam, J. S., and Siu, C. K.: Interim Report on Review of Landslip Warning Criteria, Special Projects Division, Special Project Report 4/2003, Geotechnical Engineering Office, Civil Engineering Department, SAR Government, Hong Kong, 20 pp., 2003. 